NBER WORKING PAPER SERIES

\title{
ASSET PRICING IMPLICATIONS OF FIRMS' FINANCING CONSTRAINTS
}

\author{
Joao Gomes \\ Amir Yaron \\ Lu Zhang \\ Working Paper 9365 \\ http://www.nber.org/papers/w9365

\section{NATIONAL BUREAU OF ECONOMIC RESEARCH 1050 Massachusetts Avenue} \\ Cambridge, MA 02138 \\ December 2002
}

We have benefited from helpful comments of Andy Abel, Ravi Bansal, Michael Brandt, John Cochrane, Janice Eberly, Ruediger Fahlenbrach, Burton Hollifield, Narayana Kocherlakota, Owen Lamont, Sidney Ludvigson, Valery Polkovnichenko, Tom Tallarini, Chris Telmer, an anonymous referee and seminar participants at Rochester, Wharton, NBER 2001 Summer Institute, AP Fall 2001 meeting, 2002 SED meeting, and 2002 Utah Winter Finance Conference. We are also indebted to Maria Vassalou and Christopher Polk for providing us with their data. Financial support from the Rodney L. White Center for Financial Research is gratefully acknowledged. All remaining errors are our own. The views expressed herein are those of the authors and not necessarily those of the National Bureau of Economic Research.

(C) 2002 by Joao Gomes, Amir Yaron, and Lu Zhang. All rights reserved. Short sections of text, not to exceed two paragraphs, may be quoted without explicit permission provided that full credit, including (C) notice, is given to the source. 
Asset Pricing Implications of Firms' Financing Constraints

Joao Gomes, Amir Yaron, and Lu Zhang

NBER Working Paper No. 9365

December 2002

\section{ABSTRACT}

We incorporate costly external finance in an investment-based asset pricing model and investigate whether financing frictions are quantitatively important for pricing a cross-section of expected returns. We show that common assumptions about the nature of the financing frictions are captured by a simple "financing cost" function, equal to the product of the financing premium and the amount of external finance. This approach provides a tractable framework for empirical analysis. Using GMM, we estimate a pricing kernel that incorporates the effects of financing constraints on investment behavior. The key ingredients in this pricing kernel depend not only on "fundamentals", such as profits and investment, but also on the financing variables, such as default premium and the amount of external financing. Our findings, however, suggest that the role played by financing frictions is fairly negligible, unless the premium on external funds is procyclical, a property not evident in the data and not satisfied by most models of costly external finance.

\section{Joao Gomes}

Finance Department

The Wharton School

University of Pennsylvania

Philadelphia, PA 19104

gomesj@wharton.upenn.edu
Amir Yaron

Finance Department

The Wharton School

University of Pennsylvania

Philadelphia, PA 19104

and NBER

yaron@wharton.upenn.edu

\section{Lu Zhang}

William E. Simon Graduate School of Business Administration

University of Rochester

Rochester, NY 14627

zhanglu@simon.rochester.edu 


\section{Introduction}

In this paper we ask whether financing constraints are quantitatively important in explaining a cross-section of expected returns. Specifically, we incorporate costly external finance into a production based asset pricing model similar to Cochrane $(1991,1996)$ and explore the Euler equation restrictions imposed on returns by the optimal production and investment decisions of firms.

Our findings are as follows. First, we show that standard costly external finance models can be summarized by a parsimonious "financing cost" function that is independent of the underlying sources of financial frictions (e.g., asymmetric information, costly state verification or "lemon problems") and is given by the product of the premium on external finance and the amount of external finance. Moreover, since both the financing premium and the amount of external finance can be mapped into observable data, this theoretical result also provides a tractable empirical framework to investigate the importance of financing frictions.

Our empirical results imply that either: (a) financing frictions do not play an important role behind the observed fluctuations in the cross-section of expected returns; or (b) if financing frictions are important, the true premium on external finance must be procyclical, a property not shared by standard empirical proxies such as measures of the default premium. These results are robust to alternative measures of the default premium, "fundamentals" such as profits and investment, alternative moment conditions, and alternative functional forms for the financing cost function.

The intuition for our results is simple. The empirical success of investment based asset pricing lies in the alignment of the returns on physical investment and stock returns (Cochrane (1991)). Given the cyclical behavior of fundamentals like investment and 
productivity, and the forward looking nature of firm optimization, current investment reacts to news about expected future productivity. This generates a series of investment returns that leads the cycle and is positively correlated with future profits - thus matching the observed behavior of stock returns as documented by Fama and Gibbons (1982). With costly external finance, however, an expected rise in future productivity is also associated with lower future expected financing costs since the default premium is countercyclical. This additional effect creates an incentive for firms to try to capitalize on the lower expected costs by delaying their investment response, thus changing the implied dynamics of investment returns and lowers their correlation with the observed stock returns.

Our results contribute to two strands of the literature in finance and macroeconomics. First, from an empirical asset pricing perspective, they suggest that financing variables are not an important common factor in pricing the cross-section of expected asset returns and cast doubt on the interpretation of the Fama and French $(1993,1996)$ size and book-tomarket effects as proxies for a financial distress factor. ${ }^{1}$ Instead, our evidence seems to support recent work that emphasizes the role of firm productivity and growth in generating the observed cross-sectional variations in returns. ${ }^{2}$ Our results are also consistent with the view that financial distress is mostly an idiosyncratic phenomenon that does not affect returns in a systematic way. ${ }^{3}$ Finally, our findings can also be interpreted as providing additional evidence against models of financing frictions that rely on costly external finance. ${ }^{4}$

Second, in the macroeconomic literature, several authors have argued that financing

\footnotetext{
${ }^{1}$ For example Chan, Chen, and Hsieh (1985), Chen, Roll, and Ross (1986) and Chan and Chen (1991)

${ }^{2}$ Berk, Green, and Naik (1999), Gomes, Kogan, and Zhang (2002), and Zhang (2002).

${ }^{3}$ For example, Opler and Titman (1994), Asquith, Gertner, and Sharfstein (1994) and Lamont, Polk, and Saá-Requejo (2001).

${ }^{4}$ For example a recent strand of literature has focused instead on "quantity" constraints (e.g. Kehoe and Levine (1993), Kotcherlakotta (1996), Zhang (1997), Alvarez and Jermann (2000), Albuquerque and Hopenhayn (2001), Clementi and Hopenhayn (2001), Cooley, Quadrini, and Marimon (2001), and Almeida and Campello (2002)).
} 
constraints provide a powerful propagation mechanism, through fluctuations in asset prices, to amplify exogenous shocks and thus improve the ability of business-cycles models to replicate the behavior of typical macro aggregates. ${ }^{5}$ Our findings suggest that those models' ability to match financial data is severely strained unless the implied costs of external finance are procyclical, thus placing important restrictions on the type of models of financing frictions supported by the data. ${ }^{6}$

In addition to Cochrane $(1991,1996)$, we also build on work by Restoy and Rockinger (1994) who generalize some of the results in Cochrane (1991) to an environment with investment constraints, and Bond and Meghir (1994) who characterize the effects of financing frictions on the optimal investment decisions of the firm. Our work is also related to research by Li, Vassalou and Xing (2001) who compare the performance of alternative investment growth factors in pricing the Fama and French (1993) size and book to market portfolios, and to Lettau and Ludvigson (2001) who re-examine the empirical link between aggregate investment and stock returns using information contained in consumption-to-wealth ratio.

The remainder of this paper is organized as follows. Section 2 shows that much of the existing literature on firms' financing constraints can be characterized by specifying a simple dynamic problem describing firm behavior. Section 2 also derives the expression for returns to physical investment, and its relation to stock and bond returns, which can be used to evaluate the asset pricing implications of the model. The next section describes our data sources and econometric methods, while Section 4 reports the results of our GMM tests and examines both the performance of the model and the role of financing constraints. The robustness of our results to the use of alternative data or modelling assumptions is examined

\footnotetext{
${ }^{5}$ For example Bernanke and Gertler (1989), Carlstrom and Fuerst (1997), Kiyotaki and Moore (1997), Bernanke, Gertler, and Gilchrist (2000), and den Haan, Ramey, and Watson (1999).

${ }^{6}$ Carlstrom and Fuerst (1997) also acknowledge that the ability of financing frictions models to replicate key business cycle properties leads to a procyclical financing premium.
} 
in Section 5. Finally, Section 6 offers some concluding remarks.

\section{The Model}

In this section we incorporate costly external finance in Cochrane's (1996) investmentbased asset pricing framework. We achieve this by summarizing the common properties of alternative models of financing frictions with a very weak set of restrictions on the costs of external funds. We then show that this formulation leads to a fairly simple characterization of the optimal investment decisions of the firm and derive a set of easily testable asset pricing conditions that can potentially shed light on the role of financing frictions.

\subsection{Modelling Financing Frictions}

Theoretical foundations of financing frictions have been provided by several researchers over the years and we do not attempt to provide yet another rationalization for their existence. Rather, we seek to summarize the common ground across much of the existing literature with a representation of financing constraints that is both parsimonious and empirically useful.

While exact assumptions and modelling strategies can differ quite significantly across the various models, most share the key feature that external finance (equity or debt) is more "costly" than internal funds. It is this crucial property that we explore in our analysis below by assuming that the financial market imperfections will be entirely captured by the unit costs of raising external finance.

Consider first the case of equity finance. Suppose a firm issues $N$ dollars in new shares and let $W$ denote the reduction on the claim of existing shareholders associated with the issue of one dollar of new equity. Clearly, in a Modigliani-Miller world, $W=1$ since the total value of the firm is unaffected by financing decisions. If Modigliani-Miller fails to hold 
however, new equity lowers the total value of the firm, and $W>1$. New issues are costly to existing shareholders, not only because they reduce claims on future dividends, but because they also reduce value due to the presence of additional transaction or informational costs. ${ }^{7}$

Suppose now that the firm decides to use debt financing, $B$, and let the function $R$ denote the future repayment costs of this debt. ${ }^{8}$ If Modigliani-Miller holds these repayments will just equal the opportunity cost of internal funds, captured by the relevant discount factor for shareholders, $M$. In this case we will simply have that $\mathrm{E}[M R(\cdot)]=1$, where $\mathrm{E}[\cdot]$ denotes the expectation over the relevant probability measure. Absent Modigliani-Miller, debt is more costly than internal funds and $\mathrm{E}[M R(\cdot)]>1$, at least when $B>0$.

In addition, it is often assumed that the "financing costs" are increasing in the amount of external finance, so that $\partial W(\cdot) / \partial N$ and $\partial R(\cdot) / \partial B$ are positive. It also seems reasonable to assume that the costs depend on the amount of financing normalized by firm size, $K$, which allows for the possibility that large firms will face lower financing costs. Finally, these costs may also be state-dependent. In this case we would write $W(\cdot)=W(N / K, S)$, where $S$ summarizes both firm-level and aggregate uncertainty, and similarly $R(\cdot)=R(B / K, S)$.

These additional properties are also common and fairly intuitive. We summarize them in Assumption 1.

Assumption 1 Let $S$ summarize all forms of uncertainty. The cost functions $W(\cdot)$ and $R(\cdot)$ satisfy:

$$
W(N / K, S)>1, \quad W_{1}(\cdot) \equiv \partial W(\cdot) / \partial N \geq 0 \quad \text { for } \quad N>0
$$

\footnotetext{
${ }^{7}$ E.g., Jensen and Meckling (1976), Myers and Majluf (1984), and Greenwald, Stiglitz, and Weiss (1984)

${ }^{8}$ If there is no possibility of default these costs will just equal the gross interest on the loan. If default is allowed, they may depend on the liquidation value of the firm.
} 
and

$$
\mathrm{E}_{t}[M R(B / K, S)] \geq 1, \quad R_{1}(\cdot) \equiv \partial R(\cdot) / \partial B \geq 0 \quad \text { for } \quad B>0
$$

This is a very weak assumption as it merely requires that external finance, whether debt or equity, is more expensive than internal funds, with non-decreasing unit costs.

Essentially, a large portion of the existing literature on financing constraints has focused so far on establishing the nature and properties of the functions $W(\cdot)$ and $R(\cdot)$, by concentrating on optimal contracts in the presence of transaction costs, moral hazard or asymmetric information. These alternative arguments provide different rationales, and sometimes different forms, for the functions $W(\cdot)$ and $R(\cdot)$, but most share the basic properties captured by Assumption 1. By focusing on the common ground across much of this existing literature on financing frictions, we seek to provide a fairly general test of the role that these constraints play in determining asset prices.

\subsubsection{Example: Asymmetric Information}

A very popular strand of literature focuses on the costs associated with the existence of asymmetric information between borrowers and lenders. ${ }^{9}$ Here we briefly sketch a fairly general example of this well-known class of models and show how it fits into our general approach, summarized in Assumption 1. The virtues of this popular formulation are simplicity and descriptive realism. Moreover, since debt finance accounts for $75 \%$ to $100 \%$ of the total amount of external funds used by corporate firms, this is, by far, the most empirically relevant example. ${ }^{10}$

Consider the problem of a firm that has access to stochastic technology that purchases $K$

\footnotetext{
${ }^{9}$ E.g., Townsend (1979), Gale and Hellwig (1985), Williamson (1987), Bernanke and Gertler (1989), Carlstrom and Fuerst (1997), and Bernanke, Gertler, and Gilchrist (1996, 1999).

${ }^{10}$ Source: Federal Reserve U.S. Flow of Funds Data.
} 
units of productive capacity to produce $A K$ units of output. Assume that productivity, $A$, is an i.i.d. random variable with a cumulative distribution $\Phi(\cdot)$ over a non-negative support, and an increasing hazard function $d \Phi(A) /(1-d \Phi(A)) .{ }^{11}$ Moreover, suppose that productivity is freely observed only by the firm. Lenders can only observe $A$ by paying a monitoring cost of $\mu K$ units of capital.

To finance its purchases of capital goods, the firm can use internal funds in the amount of $F$, or it can borrow an amount $B$ from a lender or a bank. It follows that the firm's resource constraint is given by $K=F+B .^{12}$ Loans are repaid, with interest $R$, after production has taken place. However, if the firm defaults, the lender seizes the entire value of production, net of monitoring costs. It follows that the firm will find it optimal to default if, and only if,

$$
A<\bar{A}=R \times B / K
$$

Gale and Hellwig (1985) show that the optimal lending contract between the two parties is one of risky debt. Formally, this is characterized by the problem:

$$
\begin{array}{ll} 
& \max \int_{\bar{A}}^{\infty}(A K-R B) d \Phi \\
\text { s.t. } & \int_{\bar{A}}^{\infty} R B d \Phi+(1-\mu) \int_{0}^{\bar{A}} A K d \Phi \geq R^{f} B
\end{array}
$$

where (3) denotes the expected payoff to the firm and (4) guarantees that the return on the loan, at least, compensates the lender for the opportunity cost of the funds, $R^{f}$. Because the lender must pay the auditing cost, $\mu K$, to observe productivity, borrowing rates will generally exceed lending rates, or the opportunity cost of funds for the lender. While a detailed characterization of this problem is available in the literature, and is quite beyond

\footnotetext{
${ }^{11}$ This property is satisfied by most c.d.f. including the normal and log-normal distributions.

${ }^{12}$ If $F>K$ we can think of $B$ as a financial asset, for example a bank deposit. Naturally, since this is not private information, its payoff is riskless.
} 
the scope of this paper, Proposition 1 derives the expression for the optimal lending rate, $R$.

Proposition 1 The optimal lending rate is given by the following expression

$$
R=\rho\left(R^{f}, B / K\right) \geq R^{f}
$$

Moreover $\rho^{\prime}(\cdot)>0$.

\section{Proof See Appendix A}

Proposition 1 establishes that this class of models falls within the general characterization summarized by Assumption 1. The interest rate on loans can be represented by an increasing function of the amount of external finance. Moreover, this rate will always exceeds the risk free rate, unless the firm does not require financing. ${ }^{13}$ Finally, in this case, the premium on external funds is entirely due to the need to compensate the lender for the costs associated with default. Clearly then, the financing premium in this model corresponds exactly to a "default" premium.

\subsection{Firm's Problem}

We now embed the costly external finance Assumption 1 within a general dynamic production asset pricing model. Accordingly, consider the problem of a firm seeking to maximize the value to existing shareholders, denoted $V$, in an environment where external finance is costly. This firm makes investment decisions by choosing the optimal amount of capital to have at the beginning of the next period, $K_{t+1}$. Investment spending, $I_{t}$, as well as dividends, $D_{t}$, can be financed with internal cash flows $\Pi\left(K_{t}, S_{t}\right)$, new equity issues, $N_{t}$, or one-period debt $B_{t+1}{ }^{14}$

\footnotetext{
${ }^{13}$ This result is quite general and holds regardless of the exact form of financing used (see Stein (2001) for a simple illustration).

${ }^{14}$ One-period debt simplifies the algebra considerably but has no bearing on our results.
} 
The problem of this firm can then be summarized by the following dynamic program:

$$
\begin{aligned}
V\left(K_{t}, B_{t}, S_{t}\right)= & \max _{\substack{D_{t}, B_{t+1}, K_{t+1}, N_{t}}}\left\{D_{t}-W\left(N_{t} / K_{t}, S_{t}\right) N_{t}+\mathrm{E}_{t}\left[M_{t, t+1} V\left(K_{t+1}, B_{t+1}, S_{t+1}\right)\right]\right\} \\
& D_{t}=C_{t}+N_{t}+B_{t+1}-R\left(B_{t} / K_{t}, S_{t}\right) B_{t} \\
& I_{t}=K_{t+1}-(1-\delta) K_{t}, \quad \delta \geq 0 \\
& C_{t}=C\left(K_{t}, K_{t+1}, S_{t}\right)=\Pi\left(K_{t}, S_{t}\right)-I_{t}-\frac{a}{2}\left[\frac{I_{t}}{K_{t}}\right]^{2} K_{t} \quad a \geq 0 \\
& D_{t} \geq \bar{D}, \quad N_{t} \geq 0
\end{aligned}
$$

where $M_{t, t+1}$ is the stochastic discount factor (of the owners of the firm) from time $t$ to $t+1$ and $\bar{D}$ is the firm's minimum, possibly zero, dividend payment. Note that firms can accumulate financial assets, in which case debt is negative. We assume that the cash flow function, $\Pi(\cdot)$, exhibits constant returns scale, but its exact form is not important.

Equation (7) shows the resource constraint of the firm. It implies that dividends must equal internal funds, net of investment spending, $C_{t}$, plus new external funds, net of debt repayments. Equation (8) is the standard capital accumulation equation, relating current investment spending, $I_{t}$, to future capital, $K_{t+1}$. We assume that old capital depreciates at the rate $\delta$. As in Cochrane $(1991,1996)$, investment requires the payment of adjustment costs, captured by the term $(a / 2)\left[I_{t} / K_{t}\right]^{2} K_{t}$.

Given our assumptions, it is immediate that the firm will only use external finance after internal cash flows are exhausted and no dividends are paid, above the required level $\bar{D}$. Conversely, dividends will exceed this minimum only if no external funds are required to finance them. Hence, the model extends the familiar hierarchical financing structure derived by Myers (1984) in a static framework to a dynamic setting. 


\subsection{Asset Pricing Implications}

To establish the asset pricing implications of the model we begin by eliminating investment by combining the constraints $(7)$ and (9). Letting $\mu_{t}$ denote the Lagrange multiplier associated with this combined constraint, the optimal first order conditions with respect to $K_{t+1}$ and $B_{t+1}$ are, respectively:

$$
\begin{aligned}
\mu_{t} C_{2}\left(K_{t}, K_{t+1}, S_{t}\right)+\mathrm{E}_{t}\left[M_{t, t+1} V_{1}\left(K_{t+1}, B_{t+1}, S_{t+1}\right)\right] & =0 \\
\mu_{t}+\mathrm{E}_{t}\left[M_{t, t+1} V_{2}\left(K_{t+1}, B_{t+1}, S_{t+1}\right)\right] & =0
\end{aligned}
$$

Rearranging yields the pricing equations:

$$
\begin{aligned}
& \mathrm{E}_{t}\left[M_{t, t+1} R_{t+1}^{I}\right]=\mathrm{E}_{t}\left[M_{t, t+1}\left(\frac{V_{1}\left(K_{t+1}, B_{t+1}, S_{t+1}\right)}{-\mu_{t} C_{2}\left(K_{t}, K_{t+1}, S_{t}\right)}\right)\right]=1 \\
& \mathrm{E}_{t}\left[M_{t, t+1} R_{t+1}^{B}\right]=\mathrm{E}_{t}\left[M_{t, t+1}\left(\frac{V_{2}\left(K_{t+1}, B_{t+1}, S_{t+1}\right)}{-\mu_{t}}\right)\right]=1
\end{aligned}
$$

where $R_{t+1}^{I}$ and $R_{t+1}^{B}$ denote the returns on physical investment and debt, respectively.

Equations (12) and (13) completely summarize of the role of financing constraints for the optimal behavior of firms. However, this characterization is extremely difficult to implement empirically, since it requires an explicit solution to the value function, $V\left(K_{t}, B_{t}, S_{t}\right)$, as well as the multiplier, $\mu_{t}$. More importantly, this procedure would require much more stringent assumptions about the functional forms of the cost functions, $W$ and $R$, than those provided in Assumption 1, thus limiting the generality of our conclusion.

Instead, we pursue an alternative approach by exploiting the fact that the solution to the problem above can be characterized by solving the following "frictionless" problem

$$
\widetilde{V}\left(K_{t}, B_{t}, S_{t}\right)=\max _{K_{t+1}}\left\{\widetilde{C}\left(K_{t}, K_{t+1}, S_{t}\right)+\mathrm{E}_{t}\left[M_{t, t+1} \widetilde{V}\left(K_{t+1}, B_{t+1}, S_{t+1}\right)\right]\right\}
$$


where $\widetilde{V}$ denotes the total value of the firm for both stock and bond holders, and cash flows are now defined by:

$$
\widetilde{C}\left(K_{t}, K_{t+1}, S_{t}\right)=C\left(K_{t}, K_{t+1}, S_{t}\right)-b\left(S_{t}\right) X_{t}
$$

where the last term equals the product of the premium on external finance, $b\left(S_{t}\right)$, and the amount of external financing used by the firm, $X_{t} \equiv B_{t+1}+N_{t}$. Note also that the resource constraint (7) implies that $X_{t}$ equals: $^{15}$

$$
X_{t} \equiv B_{t+1}+N_{t}=R_{t} B_{t}+\bar{D}-C\left(K_{t}, K_{t+1}, S_{t}\right)
$$

Proposition 2 establishes the equivalence between problem (14) and the original formulation $(6)$.

Proposition 2 Let the adjusted cash flow function $\widetilde{C}(\cdot)$ be given by (15). Then:

(i) the two dynamic programs (6) and (14) are equivalent;

(ii) financing constraints are completely summarized by the "financing cost" function:

$$
b\left(S_{t}\right) X_{t}, \quad b\left(S_{t}\right) \geq 0
$$

and, (iii) investment returns can be written as:

$$
R_{t+1}^{I}=\frac{\widetilde{C}_{1}\left(K_{t+1}, K_{t+2}, S_{t+1}\right)}{-\widetilde{C}_{2}\left(K_{t}, K_{t+1}, S_{t}\right)}=-\frac{\left(1+b\left(S_{t+1}\right)\right) C_{1}\left(K_{t+1}, K_{t+2}, S_{t+1}\right)}{\left(1+b\left(S_{t}\right)\right) C_{2}\left(K_{t}, K_{t+1}, S_{t}\right)}
$$

Proof. We present the proof for the case of equity finance only. The proof for the case with debt is provided in Appendix A. When firms have no debt $X_{t}=N_{t}$ and replacing the

\footnotetext{
${ }^{15}$ Recall that $X_{t} \geq 0$ implies $D_{t}=\bar{D}$, since it is not optimal for firms to issue new equity or debt while paying out excessive dividends.
} 
resource constraints in (6) yields:

$$
V\left(K_{t}, S_{t}\right)=\max _{K_{t+1}, N_{t}}\left\{C\left(K_{t}, K_{t+1}, S_{t}\right)-(W(\cdot)-1) N_{t}+\mathrm{E}_{t}\left[M_{t, t+1} V\left(K_{t+1}, S_{t+1}\right)\right]\right\}
$$

Letting $b(\cdot)=W\left(N_{t} / K_{t}, S_{t}\right)-1$ be the premium on external finance, it follows that:

$$
\widetilde{C}\left(K_{t}, K_{t+1}, S_{t}\right)=C\left(K_{t}, K_{t+1}, S_{t}\right)-(W(\cdot)-1) N_{t}
$$

(i) and (ii) thus follow. Part (iii) follows from the fact that

$$
\partial X_{t} / \partial K_{t}=-C_{1}(\cdot) ; \quad \partial X_{t} / \partial K_{t+1}=-C_{2}(\cdot)
$$

While the proof for the case of debt financing requires a fairly elaborate verification of integrability conditions, the basic argument of the proof lies in the characterization of the multiplier. In some sense this proposition merely explores the fact that one can always rewrite a constrained problem as an unconstrained one with embedded multipliers. What is novel here is the precise characterization of the multiplier, $\mu_{t}$, as a measure of the premium on external finance. By linking this "shadow-price" to an essentially observable variable, we are able to recast the problem in a way that is amenable to empirical analysis. Moreover, our financing cost function provides a very simple, but quite general, characterization of the financing constraints. ${ }^{16}$

\footnotetext{
${ }^{16}$ Gilchrist and Himmelberg (1998) examine the effect of financing frictions on investment by simply specifying a similar cost function. However, they do not provide a formal argument to link this representation with the underlying assumptions in models of costly external finance.
} 


\subsection{Constructing Investment Returns}

Plugging (9) into (18) yields:

$$
R_{t+1}^{I}(i, \pi, b)=\frac{\left(1+b\left(S_{t+1}\right)\right)\left(\pi_{t+1}+\frac{a}{2} i_{t+1}^{2}+\left(1+a i_{t+1}\right)(1-\delta)\right)}{\left(1+b\left(S_{t}\right)\right)\left(1+a i_{t}\right)}
$$

where $i \equiv(I / K)$ is the investment-to-capital ratio, and $\pi \equiv(\Pi / K)$ is the profits-to-capital ratio.

To gain some intuition on the role of the financing frictions, we can decompose (19) as:

$$
R_{t+1}^{I} \equiv \frac{1+b\left(S_{t+1}\right)}{1+b\left(S_{t}\right)} \hat{R}_{t+1}^{I}
$$

where $\hat{R}^{I}$ denotes the investment return with no financing costs which is entirely driven by the two "fundamentals", $i$ and $\pi$. The role of the financing frictions is then captured by the term $\frac{1+b\left(S_{t+1}\right)}{1+b\left(S_{t}\right)}$ and it depends only on the properties of the financing premium. This implementation is very appealing empirically, since it requires only a measure of the premium on external finance as well as data on the two fundamentals.

\subsection{Financing Premium}

To complete our description of investment returns all that is needed is a specification for the premium on external finance, $b\left(S_{t}\right)$.

\subsubsection{The Default Premium}

Section 2.1.1 suggests one obvious candidate: For a large class of models the premium on external funds, $b\left(S_{t}\right)$, is exactly equal to the premium necessary to compensate lenders for the possibility of default.

In addition to our formal arguments, the use of the default premium can also be justified 
by its popularity in much of the existing literature. Specifically, the ability of default premium to track movements in asset prices has long been recognized. As a consequence the default premium is a common choice in many reduced form asset pricing tests. ${ }^{17}$ In addition, the default premium is also a very good predictor of business cycle fluctuations. ${ }^{18}$ Finally, and perhaps more importantly, the default premium is also frequently used as a measure of the premium of external funds in several applications of models of financing frictions. ${ }^{19}$

Given these arguments, it seems then natural to use the default premium to construct an empirical counterpart to the theoretical premium $b(\cdot)$.

\subsubsection{Other Measures}

Although the default premium provides a set of benchmark results for our analysis we also use a variety of additional measures of the financing premium. First, Propositions 1 and 2 formally establish that the financing premium is increasing in the amount of external finance (relative to size). Given our results, this variable should be closely related to the actual financing costs, and is independent of the exact source of financing. Empirically, this means that we can also construct a good proxy for $b(\cdot)$ by looking only at the behavior of the external finance, $X / K$.

In addition, we also look at two new measures of the cost of external finance: the common factor of financial constraints constructed in Lamont, Polk, and Saa-Requejo (2001), and the aggregate default likelihood measure constructed by Vassalou and Xing (2002). These two measures are described in detail below. Together, these alternative measures complement our benchmark analysis and provide a fairly exaustive analysis of the robustness of our results.

\footnotetext{
${ }^{17}$ E.g., Fama (1981), Chen, Roll, and Ross (1986), Keim and Stambaugh (1986), Chen (1991), Fama and French (1993), and Jagannathan and Wang (1996).

${ }^{18}$ E.g., Harvey (1989), Bernanke (1990), and Stock and Watson (1989, 1999).

${ }^{19}$ E.g., Kashyap, Stein, and Wilcox (1993), Kashyap, Lamont, and Stein (1994), Bernanke and Gertler (1995), Denis and Denis (1995), and Bernanke, Gertler, and Gilchrist (1996, 1999).
} 


\subsubsection{Empirical Specification}

Our empirical analysis below, uses these two alternative approaches to construct, and estimate, our model. More specifically, our approach will be to specify that the finance premium, $b\left(S_{t}\right)$, of the form

$$
b\left(S_{t}\right)=b_{0}+b_{1} \times f_{t}
$$

where $b_{0}$ and $b_{1}$ are parameters to be estimated and $f_{t}$ is a common factor capturing financing constraints. Examples of such factors will include measures of the default premium or the ratio of external finance to capital. ${ }^{20}$

Although equation (21) seems relatively simple, the identification of the constant term, $b_{0}$, is non-trivial. This is easier to see when $b_{1}=0$. In this case $(20)$ implies that $R^{I} \equiv \hat{R}^{I}$, regardless of the actual value of $b_{0}$. Thus, regardless of its actual level, if the financing premium has no time variation, financing constraints do not affect returns. This invariance persists even when $b_{1}$ is not exactly zero. ${ }^{21}$ The intuition is simple: asset returns essentially involve first differences, thus constants, like $b_{0}$, do not affect them.

This observation has important consequences. First, it implies that to explain asset returns what matters are the dynamic properties of the financing premium (identified by $b_{1}$ ) and not the overall level (captured by $b_{0}$ ). Second, since we are not able to identify the value of $b_{0}$, our results do not shed light on the overall magnitude of the financing premium. Thus, even if financing frictions do not affect returns they can still affect investment since $b_{0}$ may not necessarily be zero.

\footnotetext{
${ }^{20}$ Note that, without measurement error our example in section 2.1.1 implies that $b(\cdot)=$ Default Premium, so that $b_{0}=0$, and $b_{1}=1$.

${ }^{21}$ This can be seen by differentiating (20) to get:

$$
\partial R_{t+1}^{I} / \partial b_{0}=\frac{b_{1}\left(d_{t+1}-d_{t}\right)}{\left(1+b_{0}+b_{1} \times d_{t}\right)^{2}} \approx 0,
$$

since $b_{1}$ is small and $\left|d_{t+1}-d_{t}\right|$ is very close to 0 .
} 
Finally, our theoretical results suggest that we should require both that the overall premium and coefficient $b_{1}$ be non-negative. We will refer to this as the "restricted" version of the model. For completeness however, we also report the results for an "unconstrained" model where the we allow $b_{1}<0$.

\section{Investment-Based Factor Pricing Models}

This section describes our empirical methodology in detail and also provides an overview of our data sources and the construction of the series of returns.

\subsection{Asset Pricing Tests}

The essence of our strategy is to use the information contained in the asset prices restrictions above to formally investigate the importance of financing constraints. As we have seen in the previous section, these restrictions are summarized by the Euler equations:

$$
\mathrm{E}_{t}\left(M_{t, t+1} R_{n, t+1}^{I}\right)=\mathrm{E}_{t}\left(M_{t, t+1} R_{l, t+1}^{B}\right)=1
$$

for investment returns, $R_{n, t+1}^{I}, n=1,2, \ldots J_{I}$, and bond returns $R_{l, t+1}^{B}, l=1,2, \ldots J_{B}$. In addition, Proposition 3 shows a similar restriction must also hold for stock returns $R_{j, t+1}^{S}$, $j=1,2, \ldots J_{S}$.

Proposition 3 Stock returns satisfy the following conditions

$$
\begin{array}{r}
\mathrm{E}_{t}\left(M_{t, t+1} R_{t+1}^{S}\right)=1 \\
R_{t+1}^{I}=\omega_{t} R_{t+1}^{S}+\left(1-\omega_{t}\right) R_{t+1}^{B}
\end{array}
$$

where $\left(1-\omega_{t}\right)$ is the leverage ratio. 


\section{Proof See Appendix A}

Although the proof is somewhat elaborate, equation (25) merely states that investment returns are a weighted average of stock and bond returns. Given (23) and (25) it is immediate to verify that stock returns must satisfy the moment condition (24).

Equations (23)-(25) offer two alternative ways to examine the asset pricing implications of financing frictions. The identity (25) focuses on ex-post returns, while the Euler equations (23) and (24) are about expected returns. Thus, firm-specific risks may play an important role in examining the former, but only systematic risk is relevant for the latter. ${ }^{22}$

Specifically, we follow Cochrane (1996) and use a pricing kernel that depends only on the returns to aggregate investment and a bond index:

$$
M_{t, t+1}=l_{0}+l_{1} R_{t+1}^{I}+l_{2} R_{t+1}^{B}
$$

a specification that only requires individual returns to be approximately linear in aggregate returns. $^{23}$

The role of financing constraints in explaining the cross-section of expected returns as a common factor is captured by its influence on $R^{I}$ in the pricing kernel (26). As with any asset pricing model, financial frictions will be relevant for the pricing of expected returns only to the extent that they provide a common factor - in this context one associated with financial distress as systematic (aggregate) risk, e.g. Chan and Chen (1991) and Fama and French (1992, 1993, 1996) — that can potentially influence the stochastic discount factor. Cross-

\footnotetext{
${ }^{22}$ In Gomes, Yaron, and Zhang (2002) we investigate the importance of financing constraints on both systematic and idiosyncratic components of risk by testing the restriction (25) using panel data.

${ }^{23}$ From Harrison and Kreps (1979) and Hansen and Richard (1987) we know that one pricing kernel that satisfies (23) is $M_{t, t+1}=\sum_{j} l_{j} R_{j}^{S}+\sum_{n} l_{n} R_{n}^{I}+\sum_{l} l_{l} R_{l}^{B}$. Stock returns can be eliminated since (25) implies that only two of these returns are independent. For using aggregate investment return, we formally only need that $R_{d, t+1}^{I} \approx \gamma_{d}^{0}+\gamma_{d}^{1} R_{t+1}^{I}+\epsilon_{d, t+1}$ for portfolio $d$ and the $\epsilon_{d, t+1}$ be i.i.d. This is only a statement about technologies and not about market completeness, and it appears reasonable provided that the level of portfolio disaggregation is not too fine.
} 
sectional variations in firms's financing constraints may be important in pricing asset returns only to the extent that they affect the aggregate systematic risk. Unlike the consumptionbased literature on asset pricing, where the use of the cross-sectional distribution was motivated by the lack of success of aggregate consumption-based models (see, for example, Constantinides and Duffie, 1996), aggregate investment returns actually work very well in pricing the cross-section of returns (Cochrane, 1996); thus, the scope for firm heterogeneity affecting the systematic risk for financial distress seems fairly limited.

As we can see from (19), information about the degree of financial frictions is contained in investment returns, which will then serve as a factor capturing the extent to which aggregate financial conditions are priced. In this sense, our formulation is essentially a structural version of an APT-type framework in which one of the factors proxies for an aggregate distress variable (and where different portfolios have varying loadings on this factor), such as that taken in Fama and French $(1993,1996)$ and Lamont, Polk, and Saá-Requejo (2000). However, the relative merit of our structural approach is that it can not only answer the question of whether financing constraints affect expected returns, but also shed light on questions like how and why they affect returns.

To sum up, our metric for evaluating whether financing frictions are important is whether they show as a common factor or affect systematic risk for the cross-section of returns. This seems standard from the perspective of asset pricing.

\subsection{Econometric Methodology}

Our estimation strategy allows us to estimate factor loadings, $\mathbf{l}$, as well as the parameters, $a$ and $b$, by utilizing $M$ as specified in (26) in conjunction with moment conditions (23).

We follow Cochrane's (1996) estimation techniques for assessing the asset pricing 
implications of our model. Specifically, three alternative sets of moment conditions in implementing (23) are examined. First, we look at the relatively weak restrictions implied by the unconditional moments. We then focus on the conditional moments by scaling returns with instruments, and finally we look at time variation in the factor loadings, by scaling the factors.

For the unconditional factor pricing we use standard GMM procedures to minimize a weighted average of the sample moments (23). Letting $\sum_{T}$ denote the sample mean, we can rewrite these moments, $\mathbf{g}_{T}$ as:

$$
\mathbf{g}_{T} \equiv \mathbf{g}_{T}\left(a, b_{0}, b_{1}, \mathbf{l}\right) \equiv \sum_{T}[M \mathbf{R}-\mathbf{p}]
$$

where $\mathbf{R}=\left[R^{S}, R^{I}\left(\mathbf{y} ; a, b_{0}, b_{1}\right), R^{B}\right]$ is the menu of asset returns being priced, $\mathbf{p}=[\mathbf{1}, 1,1]$ is a vector of prices, and $\mathbf{y}=(i, \pi, d)$. One can then choose $\left(a, b_{0}, b_{1}, \mathbf{l}\right)$ to minimize a weighted sum of squares of the pricing errors across assets:

$$
J_{T}=\mathbf{g}_{T}^{\prime} \mathbf{W} \mathbf{g}_{T}
$$

A convenient feature of our setup is that, given the cost parameters, the criterion function above is linear in $\mathbf{l}$ - the factor loading coefficients. Standard $\chi^{2}$ tests of over-identifying restrictions follow from this procedure. This also provides a natural framework to assess whether the loading factors or technology parameters are important for pricing assets. ${ }^{24}$

It is straightforward to include the effects of conditioning information by scaling the returns by instruments. The essence of this exercise lies in extracting the conditional implications of (23) since, for a time-varying conditional model, these implications may

\footnotetext{
${ }^{24}$ Note that the investment return appears both in the pricing kernel and the menu of assets being priced. As Cochrane (1996) notes, this consistency is required so that investment returns do not have arbitrary properties.
} 
not be well captured by a corresponding set of unconditional moment restrictions as was noted by Hansen and Richard (1987).

To test conditional predictions of (23), we expand the set of returns to include returns scaled by instruments to obtain the moment conditions:

$$
\mathrm{E}\left[\mathbf{p}_{t} \otimes \mathbf{z}_{t}\right]=\mathrm{E}\left[M_{t, t+1}\left(\mathbf{R}_{t+1} \otimes \mathbf{z}_{t}\right)\right]
$$

where $\mathbf{z}_{t}$ is some instrument in the information set at time $t$ and $\otimes$ denotes Kronecker product.

A more direct way to extract the potential non-linear restrictions embodied in (23) is to let the stochastic discount factor be a linear combination of factors with weights that vary over time. That is, the vector of factor loadings $\mathbf{l}$ is a function of instruments $\mathbf{z}$ that vary over time. ${ }^{25}$ Therefore, to estimate and test a model in which factors are expected to price assets only conditionally, we simply expand the set of factors to include factors scaled by instruments. The stochastic discount factor utilized in estimating (23) is then,

$$
M_{t, t+1}=\left[l_{0}+l_{1} R_{t+1}^{I}+l_{2} R_{t+1}^{B}\right] \otimes z_{t}
$$

Finally, to circumvent the identification issue discussed in Section 2.5, we set $b_{0}$ beforehand to such that the implied share of the financing costs in investment positive and always equal to $3 \%$. We also show that, as expected, our results are not affected by this particular choice.

\footnotetext{
${ }^{25}$ With sufficiently many powers of $z^{\prime} s$ the linearity of $l$ can actually accommodate nonlinear relationships.
} 


\subsection{Data}

This section provides an overview of the data used in our study. A more detailed description is provided in Appendix B. Our data for the economic aggregates comes from NIPA and the Flow of Funds Accounts. Information about financial assets is obtained from CRSP and Ibbotson. The construction of investment returns requires data on profits, investment and capital. Capital consumption data is used to compute the time series average of the depreciation rate and pin down the value of $\delta$, the only technology parameter that we do not formally estimate. To avoid measurement problems due to chain weighting in the earlier periods our sample starts in the first quarter of 1954 and ends in the last quarter of 2000. Since models of financing frictions are usually applied to non-financial firms we first construct series on investment, capital and profits of the Non-Financial Corporate Sector. For comparison purposes, we also report results for the aggregate economy. Investment data are quarterly averages, while asset returns are from the beginning to the end of the quarter. As a correction, we follow Cochrane (1996) and average monthly asset returns over the quarter and then shift them so they go from approximately the middle of the initial quarter to the middle of the next quarter. ${ }^{26}$

In order to implement the estimation procedure, we require a sufficient number of moment conditions. As described above, we limit ourselves to examining the model's implications for aggregate investment and bond returns. This means that we need to look at more than just the aggregate stock return. Thus, we focus on the ten size portfolios of NYSE stock returns. Table 1 reports the summary statistics of these asset returns. In addition, we also provide results for the 25 Fama and French (1993) size and book-to-market portfolio. Bond data comes from Ibbotson's index of Long Term Corporate Bonds. The default premium

\footnotetext{
${ }^{26}$ See also Lamont (2001) and Lettau and Ludvigson (2001) for a discussion of the important consequences of aligning investment and asset returns.
} 
Table 1 : Summary Statistics of the Assets Returns in GMM

\begin{tabular}{|c|c|c|c|c|c|c|c|c|c|c|c|c|c|}
\hline & \multicolumn{10}{|c|}{ Decile Returns } & \multirow[t]{2}{*}{ vwret } & \multirow[t]{2}{*}{$R^{f}$} & \multirow{2}{*}{$\begin{array}{c}R^{B} \\
\text { mean }\end{array}$} \\
\hline & 1 & 2 & 3 & 4 & 5 & 6 & 7 & 8 & 9 & 10 & & & \\
\hline mean & 11.80 & 9.49 & 9.03 & 9.07 & 8.50 & 8.57 & 7.67 & 8.16 & 7.34 & 6.64 & 7.10 & 1.86 & 0.72 \\
\hline std & 19.61 & 17.49 & 16.73 & 16.16 & 15.49 & 15.19 & 14.51 & 13.80 & 12.90 & 11.35 & 11.87 & 1.32 & 7.11 \\
\hline Sharpe & 0.60 & 0.54 & 0.53 & 0.55 & 0.54 & 0.56 & 0.52 & 0.58 & 0.56 & 0.57 & 0.58 & 0.00 & 0.10 \\
\hline$\rho(1)$ & 0.26 & 0.29 & 0.29 & 0.31 & 0.29 & 0.28 & 0.32 & 0.27 & 0.27 & 0.36 & 0.33 & 0.67 & 0.30 \\
\hline
\end{tabular}

This table reports the means, volatilities, Sharpe ratios, and first-order autocorrelations of excess returns of deciles 1-10, excess value-weighted market return (vwret), real t-bill rate $\left(R^{f}\right)$, and excess corporate bond return $\left(R^{B}\right)$. These returns are used in GMM estimation and tests. The sample period is from 1954:2Q to 2000:3Q. Means and volatilities are in annualized percent.

is defined as the difference between the yields on BAA and AAA corporate bonds, both obtained from DRI. As an alternative we also use the spread between BAA and long term government bonds yields.

Conditioning information comes from two sources: the term premium, defined as the yield on ten year notes minus that on three-month Treasury Bills, and the dividend-price ratio of the equally weighted NYSE portfolio. We follow Cochrane (1996) and limit the number of moment conditions and scaled factors in three ways: (i) we do not scale the Treasury-Bill return by the instruments since we are more interested in the time-variation of risk premium than that of risk-free rate. (ii) Instruments themselves are not included as factors. (iii) We use only deciles one, three, eight, and ten in the conditional estimates.

\section{Results}

\subsection{GMM Estimates}

It seems natural to expect that the financing premium shows a positive correlation with the observed default premium, or the financing premium is countercyclical, since it may be more expensive for firms to issue debt and equity in recessions. This suggests that we can expect 
$b_{1} \geq 0$. We will refer to this as the "restricted" version of the model, as opposed to the "unrestricted" version.

Table 2 reports iterated GMM estimates and tests for both the unrestricted and restricted $\left(b_{1} \geq 0\right)$ versions of the benchmark models, unconditional, conditional, and scaled factor. In all cases, we use the default premium, defined as the difference between the yields on BAA and AAA corporate bonds, as our common factor in the financing premium equation (21).

As we discussed above, to circumvent the difficulties in the identifying $b_{0}$ we fix its value so that the share of financing costs in investment is always 3\%. Table 3 however, confirms that our results are almost unchanged for a wide range of values for this parameter. ${ }^{27}$ In all cases we report the value of the parameters $a$ and $b_{1}$ as well as the estimated loadings $\mathbf{l}$ and corresponding $t$-statistics. Also included are the results of $J$ tests on the model's overall ability to match the data, and the corresponding $p$-values.

Overall, our model is very successfull in pricing the cross-section of returns. In spite of the inclusion of the last few years of stock market data, the model cannot be rejected using the overidentifying restriction tests, $J_{T}$. The root mean squared errors (RMSE, mean return less predicted mean return) are all low — suggesting the statistical significance of the $J$ tests is not due to an excessively large covariance matrix. ${ }^{28}$ Figure 1 confirms this good fit by showing the close alignment between actual and predicted mean excess returns from first stage estimation. In addition, the hypothesis that all factor loadings are zero is almost always rejected at the standard 5\% significance level. Finally, the estimated loadings on corporate bond returns are usually statistically insignificant, suggesting a relatively minor role in pricing financial assets. Hence, our results are mainly driven by the properties of investment returns, $R^{I}$.

\footnotetext{
${ }^{27}$ First-stage estimates are also very similar, particularly those concerning the role of financing costs.

${ }^{28} \mathrm{RMSE}$ are reduced by half if we truncate our sample in 1997.
} 
Table 2 : GMM Estimates and Tests in the Benchmark Case

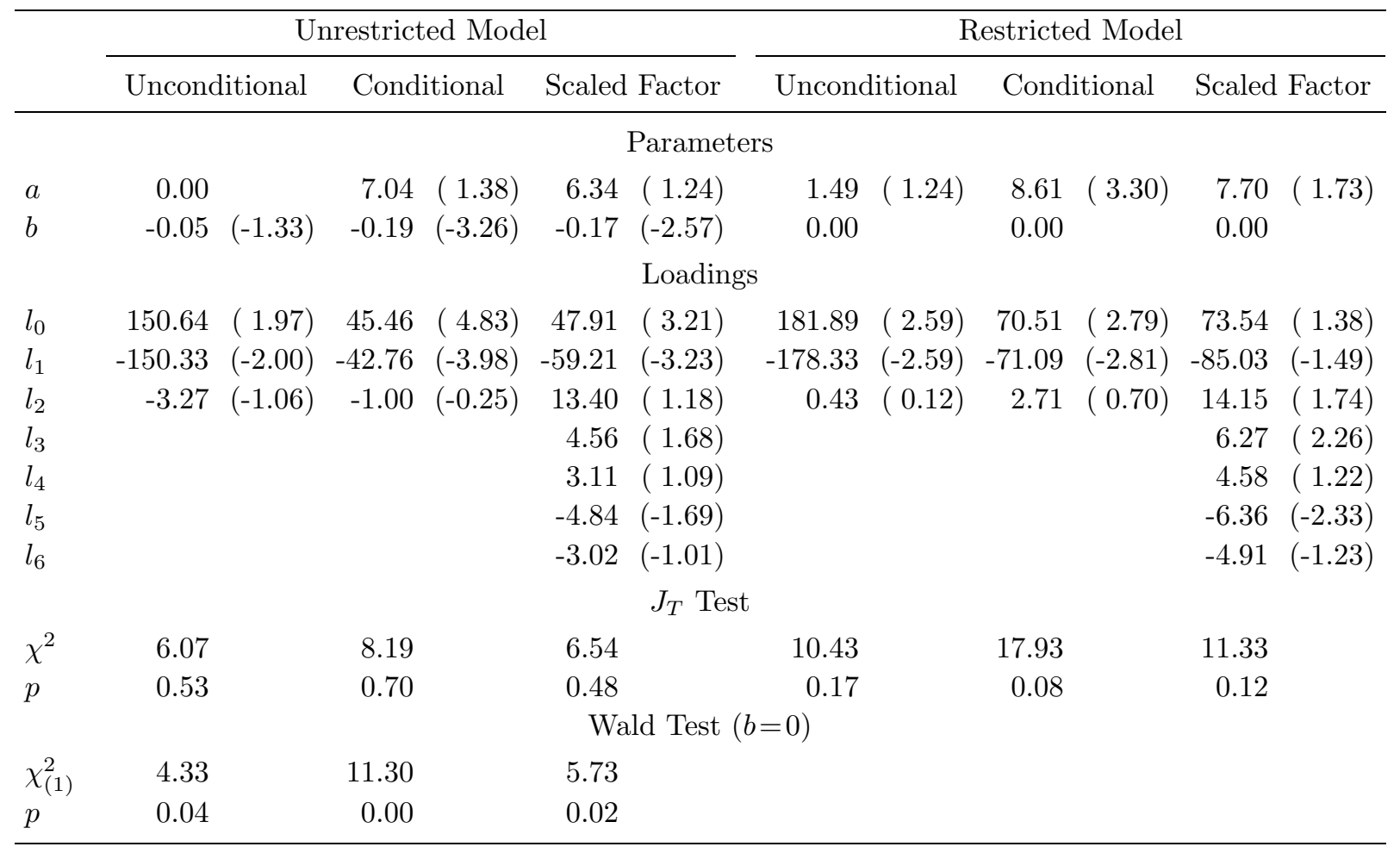

This table reports GMM estimates and tests of both the unrestricted and restricted versions of the benchmark model with linear financing cost function. In the unrestricted model, $b\left(S_{t}\right)=b_{0}+b_{1} \times d_{t}$, where $b_{1}$ is allowed to be negative and $\mathrm{d}_{t}$ is the default premium, defined as the difference between the yields on Baa and Aaa corporate bonds. In the restricted model, $b\left(S_{t}\right)=b_{0}+b_{1} \times d_{t}$, where $b_{1}$ is restricted to be nonnegative. In both cases, $b_{0}$ is chosen such that the implied share of financing cost in investment expenditure is $3 \%$. We report the estimates for $a, b_{1}$, and the loadings $l$ 's in the pricing kernel, the $\chi^{2}$ statistic and corresponding $p$-value for the $J_{T}$ test on over-identification, and $\chi^{2}$ statistic and $p$-value of the Wald test on the null hypothesis that $b_{1}=0 . t$-statistics are reported in parentheses to the right of parameter estimates. GMM estimates and tests are conducted for the unconditional, unscaled and scaled conditional model. The unconditional model uses as moment conditions the excess returns of 10 CRSP size decile portfolio and one excess investment return (over corporate bond return) and the corporate bond return (12 moment conditions). The unscaled and scaled conditional models use the excess returns of size deciles 1, 3, 8, 10, and excess investment returns (over corporate bond return), scaled by instruments, and the corporate bond return (16 moment conditions). Instruments are the constant, term premium $(t p)$, and equally weighted dividend-price ratio $(d p)$. The pricing kernel is $M=l_{0}+l_{1} R^{I}+l_{2} R^{B}$ for the unconditional and conditional models where $R^{I}$ is real investment return and $R^{B}$ is real corporate bond return. The pricing kernel is: $M=l_{0}+l_{1} R^{I}+l_{2} R^{B}+l_{3}\left(R^{I} \cdot t p\right)+l_{4}\left(R^{I} \cdot d p\right)+l_{5}\left(R^{B} \cdot t p\right)+l_{6}\left(R^{B} \cdot d p\right)$ for the scaled factor model. Investment return series are constructed from the flow-of-fund accounts using nonfinancial profits before tax. 
Table 3 : GMM Estimates and Tests with Varying Levels of Financing Cost

\begin{tabular}{|c|c|c|c|c|c|c|c|c|c|c|}
\hline & \multicolumn{10}{|c|}{ Panel A: Low Share 1\% } \\
\hline & \multicolumn{6}{|c|}{ Unrestricted Model } & \multicolumn{4}{|c|}{ Restricted Model } \\
\hline & \multicolumn{2}{|c|}{ Unconditional } & \multicolumn{2}{|c|}{ Conditional } & \multicolumn{2}{|c|}{ Scaled Factor } & \multicolumn{2}{|c|}{ Unconditional } & Conditional & Scaled Factor \\
\hline \multicolumn{11}{|c|}{ Parameters } \\
\hline$a$ & 0.00 & & 7.03 & ( 1.38$)$ & 6.37 & $(1.25)$ & 1.51 & $(1.25)$ & $8.61 \quad(3.30)$ & $7.75 \quad(1.73)$ \\
\hline$b$ & -0.05 & $(-1.33)$ & -0.18 & $(-3.26)$ & -0.16 & $(-2.58)$ & 0.00 & & 0.00 & 0.00 \\
\hline \multicolumn{11}{|c|}{$J_{T}$ Test } \\
\hline$\chi^{2}$ & 6.07 & & 8.19 & & 6.52 & & 10.51 & & 17.94 & 11.38 \\
\hline$p$ & 0.53 & & 0.70 & & 0.48 & & 0.16 & & 0.08 & 0.12 \\
\hline \multicolumn{11}{|c|}{ Wald Test $(b=0)$} \\
\hline$\chi_{(1)}^{2}$ & 4.33 & & 11.29 & & 5.74 & & & & & \\
\hline$p$ & 0.04 & & 0.00 & & 0.02 & & & & & \\
\hline & \multicolumn{10}{|c|}{ Panel B: High Share 10\% } \\
\hline & \multicolumn{6}{|c|}{ Unrestricted Model } & \multicolumn{4}{|c|}{ Restricted Model } \\
\hline & Uncol & ditional & Cons & itional & Scale & Factor & Uncor & ditional & Conditional & Scaled Factor \\
\hline \multicolumn{11}{|c|}{ Parameters } \\
\hline$a$ & 0.00 & & 7.04 & $(1.37)$ & 6.33 & $(1.24)$ & 1.50 & $(1.25)$ & $8.61 \quad(3.30)$ & $7.75 \quad(1.74)$ \\
\hline$b$ & -0.06 & $(-1.32)$ & -0.22 & $(-3.26)$ & -0.19 & $(-2.57)$ & 0.00 & & 0.00 & 0.00 \\
\hline \multicolumn{11}{|c|}{$J_{T}$ Test } \\
\hline$\chi^{2}$ & 6.08 & & 8.20 & & 6.54 & & 10.46 & & 17.93 & 11.37 \\
\hline$p$ & 0.53 & & 0.70 & & 0.48 & & 0.16 & & 0.08 & 0.12 \\
\hline \multicolumn{11}{|c|}{ Wald Test $(b=0)$} \\
\hline$\chi_{(1)}^{2}$ & 4.33 & & 11.31 & & 5.73 & & & & & \\
\hline$p$ & 0.04 & & 0.00 & & 0.02 & & & & & \\
\hline
\end{tabular}

This table reports GMM estimates and tests of both the unrestricted and restricted models with varying levels of financing cost. In contrast to the benchmark case reported in Table 2 where $b_{0}$ is chosen such that the implied shared of financing cost in investment expenditure is 3\%, Panel A reports the GMM estimates and tests for the Low Share case where $b_{0}$ is chosen such that the implied share of financing cost in investment is only $1 \%$. Panel B does the same for the High Share case where the implied share of financing cost in investment is $10 \%$. We report the estimates for $a$ and $b_{1}$, the $\chi^{2}$ statistic and corresponding $p$-value for the $J_{T}$ test on over-identification, and $\chi^{2}$ statistic and $p$-value of the Wald test on the null hypothesis that $b_{1}=0 . t$-statistics are reported in parentheses to the right of parameter estimates. The pricing kernel and the set of moment conditions are the same as in the benchmark case reported in Table 2 . 


\section{Figure 1 : Predicted Versus Actual Mean Excess Returns}

This figure plots the mean excess returns against predicted mean excess return, both of which are in \% per quarter, for conditional model (Panel A), conditional model (Panel B), and scaled factor model (Panel C). All plots are from first-stage GMM estimates.

Panel A: Unconditional Estimates

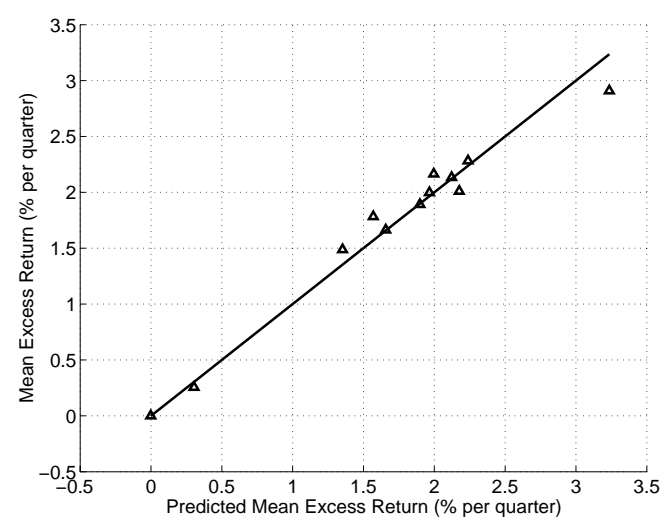

Panel B: Conditional Estimates

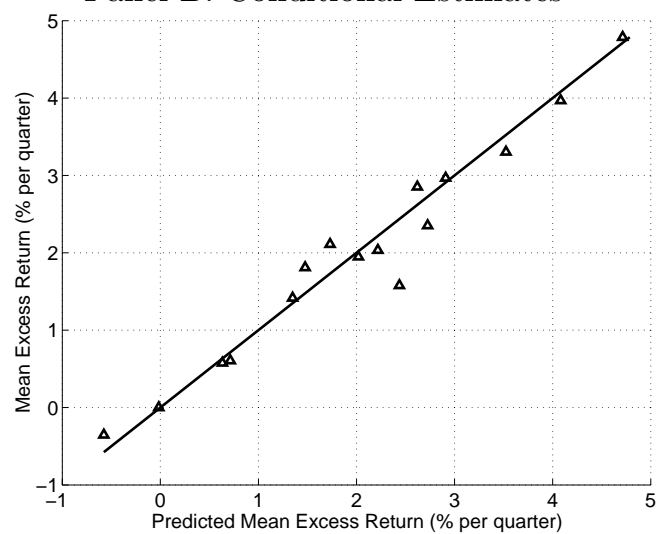

Panel C: Scaled Factor

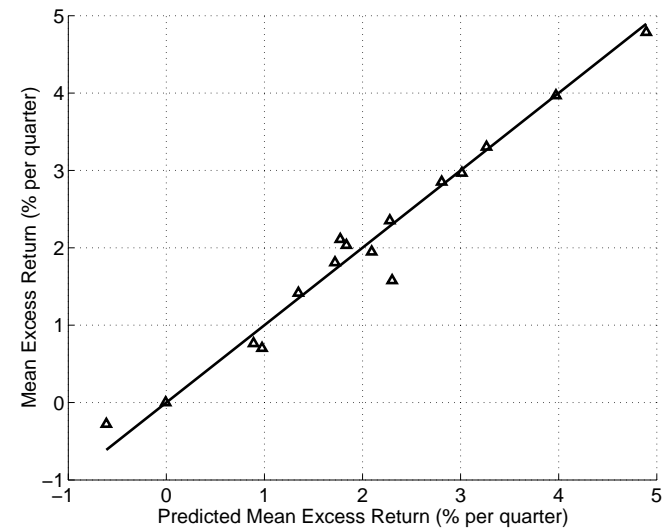


Although our model uses only a single aggregate investment return as a pricing factor (in addition to the bond returns) these results are generally comparable to Cochrane's (1996) findings. The reason for this empirical success is that our construction of investment returns, $R^{I}$, uses independent information on variations in the marginal productivity of capital, $\pi_{t}$, and investment, $i_{t}$. Cochrane (1996), on the other hand, abstracts from the variation in the marginal productivity of capital in constructing investment returns and uses instead two separate investment series (residential and non-residential) to construct two investment returns. ${ }^{29}$

\subsection{The Effect of Financing Constraints}

The focus of our analysis, however, is the role of the financing cost parameters. Table 2 shows that the unrestricted estimate yields a negative value for $b_{1}$ which implies that the financing premium must have a negative correlation with the default premium. If we restrict the choices to be nonnegative as in the restricted model, then we always obtain that $b_{1}$ is exactly zero! As we have argued above, even if $b_{1}$ is not zero, it is not possible to identify the actual level of the financing premium.

Depending upon whether one finds the non-negativity constraint on $b_{1}$ plausible, we can offer two possible interpretations for the above findings. Clearly, if one believes that the financing premium should be closely related to the default premium $\left(b_{1} \geq 0\right)$, then the simplest explanation of our findings seems to be that financing factors are not very useful in explaining the cross-section of expected returns. On the other hand, if financing factors are an important component of expected returns, then the financing premium must behave very differently from the observed default premium.

\footnotetext{
${ }^{29}$ Economically, our estimates for $a$ also seem sensible, implying adjustment costs around 8-9\% of total investment spending.
} 


\subsubsection{The Role of Financing Premium}

To understand the role of the financing premium it is useful to return to our decomposition of investment returns in (20). Figure 2 displays the correlation structure between the growth rate in the default premium $d_{t+1} / d_{t}$, stock returns, $R_{t+1}^{S}$, and investment returns $R_{t+1}^{I}$ for different levels of $b_{1}$, with leads and lags of the two fundamentals, $i_{t}$ (Panel A) and $\pi_{t}$ (Panel B).

In both panels, the pattern of $\hat{R}^{I}$ (when $b_{1}=0$ ) is very similar to the observed $R^{S}$. Both returns lead future economic activity, while their contemporaneous correlation with fundamentals is somewhat low. As Cochrane (1991) notes, this is to be expected if firms adjust current investment in response to an anticipated rise in future productivity. The behavior of the default premium, however, is quite different. Its negative correlation with future economic activity implies a series of investment returns that behaves quite unlike observed stock returns, thus making $R_{t+1}^{I}$ with a positive (negative) $b_{1}$ less (more) useful as a pricing factor.

The intuition is as follows. Since a rise in expected future productivity (or profits) is associated with an expected decline in the financing premia (because of its counter-cyclical properties), there is an incentive for the firm to delay its investment response in the presence of financing constraints. From equation (19) we learn that this lowers investment returns. As Figure 2 shows, this makes it more difficult for investment returns to match the observed pattern of stock returns.

To summarize, productivity and financing costs provide two competing forces that determine the reaction of investment, and hence investment returns, to business cycle conditions. On the one hand, productivity implies that firms should respond by investing immediately. On the other hand, since the future entails lower financing costs, firms should 
Figure 2 : Correlation Structure

This figure presents the correlations of investment returns $R^{I}$, real value-weighted market return $R^{S}$, the growth rate of default premium $d_{t+1} / d_{t}$ with $I / K$ and $\Pi / K$ with various leads and lags. Panel A plots the correlation structure of the above series with $I / K$ and Panel B plots that with $\Pi / K$. In the graphs, $b$ is the slope term in the specification of financing premium (21), and the intercept term is set such that the implied share of financing cost in investment is $3 \%$.

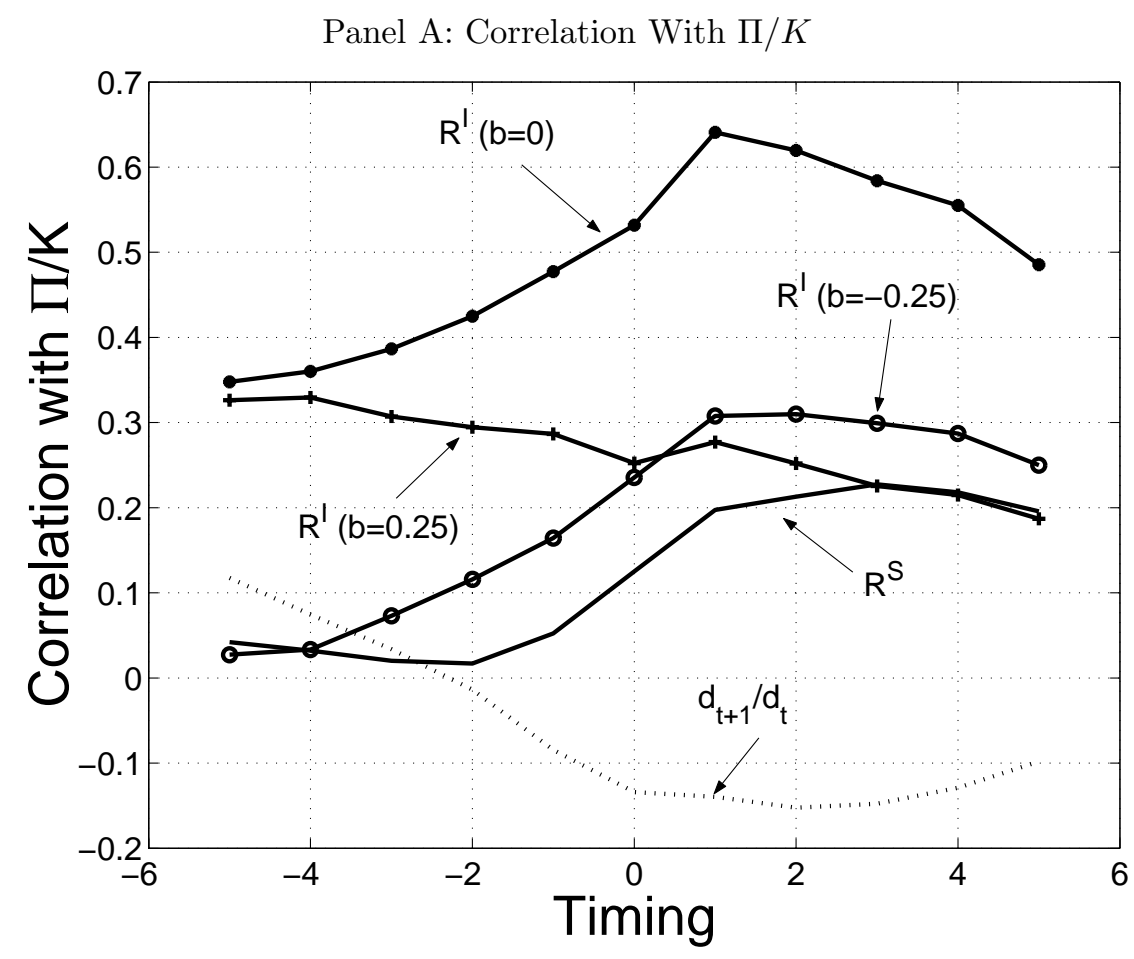

Panel B: Correlation With $I / K$

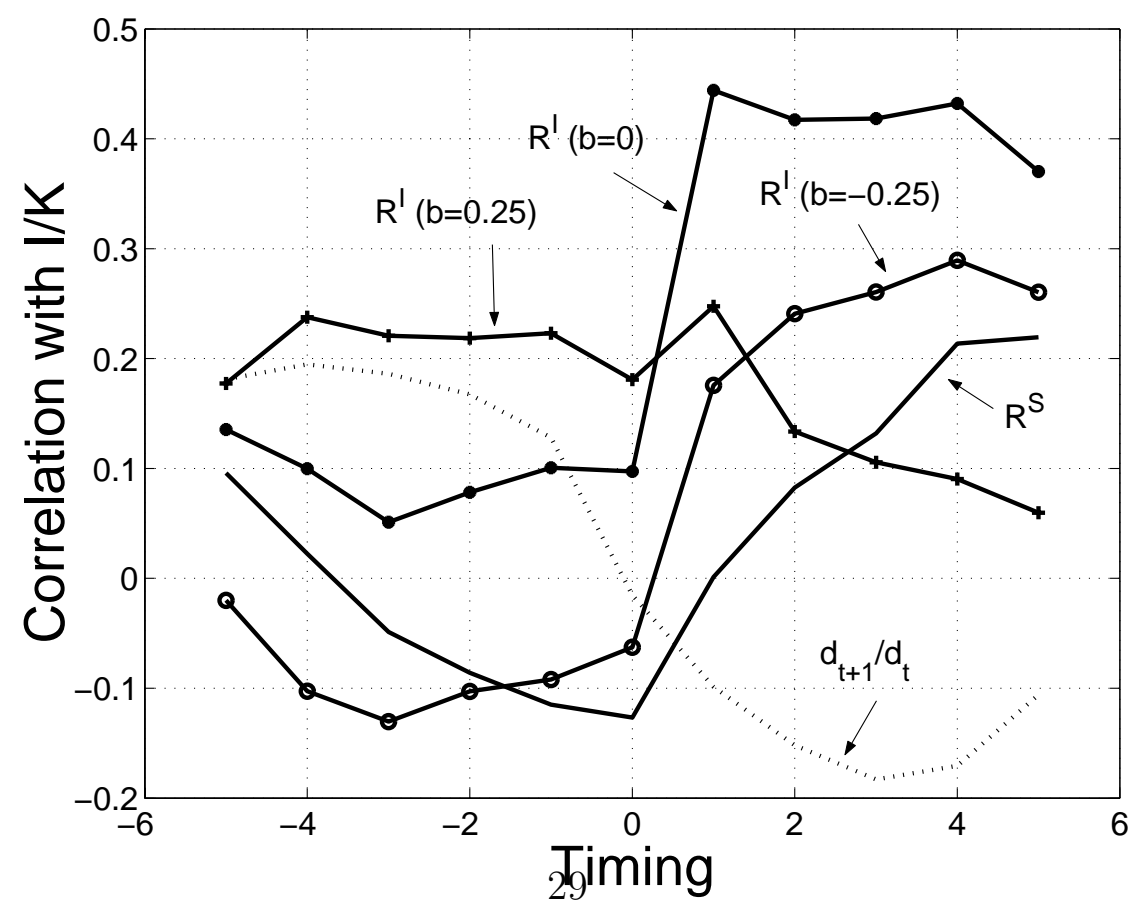


delay investment. Figure 2 shows that consistency with asset return data requires the financing channel to be unimportant, unless the financing premium is procyclical, i.e., $b_{1}<0$.

Figure 2 also suggests that these results are not likely to rely on timing issues such as those created by the existence of time-to-plan (or perhaps time-to-finance in this context). ${ }^{30}$ The reason is that there is no obvious phase shift between the premium and the return series. What seems crucial is the countercyclical pattern of the premium on external finance, induced by the behavior of the default premium. This is why we obtain a negative value for $b_{1}$ in the unrestricted version of our model.

\subsubsection{Properties of the Pricing Kernel}

Table 4 provides additional intuition for our results by examining the effect of financing frictions on the pricing kernel and the pricing errors. It describes the effects of increasing the value of $b_{1}$ above 0 in each set of moment conditions, while $a$ is kept constant at its optimal level reported Table 2.

As we can readily observe, a countercyclical financing premium lowers the market price of risk $\sigma(M) / E(M)$, as well as the (absolute) correlation between the pricing kernel and valueweighted returns for all three models, thus deteriorating the performance of the pricing kernel. Perhaps more direct evidence is given by examining the implied pricing errors. A simple way of doing this is to compute the beta representation:

$$
R_{i}-R_{f}=\alpha_{i}+\beta_{1 i}\left(R^{I}-R_{f}\right)+\beta_{2 i}\left(R^{B}-R_{f}\right)
$$

Given the assumed structure of the pricing kernel this representation exists, with $\alpha_{i}=0$ (see the discussion in Cochrane, 2001). Therefore, large values of $\alpha$ are evidence against the model. Table 4 reports the implied $\alpha$ s for the regressions on both small firms (NYSE decile

\footnotetext{
${ }^{30}$ This issue is analyzed by Lamont (2000) in an asset pricing context.
} 
Table 4 : Properties of Pricing Kernels, Jensen's $\alpha$, and Investment Returns

\begin{tabular}{|c|c|c|c|c|c|c|c|c|c|c|}
\hline \multirow[b]{2}{*}{$b$} & \multicolumn{2}{|c|}{ Pricing Kernel } & \multicolumn{4}{|c|}{ Jensen's $\alpha$} & \multicolumn{4}{|c|}{ Investment Return } \\
\hline & $\frac{\sigma[M]}{\mathrm{E}[M]}$ & $\rho_{M, R^{S}}$ & $\alpha^{v w}$ & $t_{\alpha}^{v w}$ & $\alpha^{d 1}$ & $t_{\alpha}^{d 1}$ & mean & $\sigma_{R^{I}}$ & $\rho(1)$ & $\rho_{R^{I}, R^{s}}$ \\
\hline & \multicolumn{10}{|c|}{ Unconditional Model } \\
\hline 0.00 & 0.82 & -0.28 & 0.26 & 0.35 & 1.02 & 0.78 & 6.55 & 0.97 & 0.76 & 0.30 \\
\hline 0.15 & 0.57 & -0.03 & 3.03 & 4.94 & 5.69 & 5.45 & 6.56 & 1.70 & 0.38 & -0.31 \\
\hline \multirow[t]{2}{*}{0.30} & 0.58 & -0.07 & 3.07 & 6.22 & 5.58 & 6.66 & 6.58 & 2.98 & 0.31 & -0.41 \\
\hline & \multicolumn{10}{|c|}{ Conditional Model } \\
\hline 0.00 & 0.75 & -0.29 & 0.16 & 0.30 & 0.68 & 0.77 & 5.91 & 2.24 & 0.09 & 0.35 \\
\hline 0.15 & 0.37 & 0.39 & 1.46 & 2.70 & 3.01 & 3.25 & 5.92 & 2.23 & 0.00 & -0.01 \\
\hline \multirow[t]{2}{*}{0.30} & 0.79 & 0.17 & 2.22 & 4.51 & 4.21 & 5.02 & 5.93 & 3.05 & 0.10 & -0.24 \\
\hline & \multicolumn{10}{|c|}{ Scaled Factor Model } \\
\hline 0.00 & 0.81 & -0.36 & 0.03 & 0.06 & 0.51 & 0.55 & 6.02 & 1.99 & 0.14 & 0.36 \\
\hline 0.25 & 0.67 & -0.06 & 1.63 & 2.92 & 3.35 & 3.48 & 6.03 & 2.06 & 0.06 & -0.05 \\
\hline 0.50 & 0.61 & 0.01 & 2.38 & 4.79 & 4.48 & 5.30 & 6.04 & 2.98 & 0.15 & -0.27 \\
\hline
\end{tabular}

This table reports, for each combination of parameters $a$ and $b$, properties of the pricing kernel, including market price of risk $(\sigma[M] / \mathrm{E}[M])$, the contemporaneous correlation between pricing kernel and real market return $\left(\rho_{M, R^{S}}\right)$, Jensen's $\alpha$ and its corresponding $t$-statistic $\left(t_{\alpha}\right)$, summary statistics of investment return, including mean, volatility $\left(\sigma_{R^{I}}\right)$, first-order autocorrelation $(\rho(1))$, and correlation with the real valueweighted market return $\left(\rho_{R^{I}, R^{S}}\right)$. Jensen's $\alpha$ is defined from the following regression:

$$
R^{p}-R^{f}=\alpha+\beta_{1}\left(R^{I}-R^{f}\right)+\beta_{2}\left(R^{B}-R^{f}\right)
$$

where $R^{p}$ is either real value-weighted market return $\left(R^{v w}\right)$ or real decile one return $\left(R^{1}\right), R^{f}$ is real interest rate proxied by real treasury-bill rate, $R^{I}$ is investment return, and $R^{B}$ is real corporate bond return. In each case the cost parameters $a$ 's are held fixed at the GMM estimates. 
1) and value-weighted returns. It displays a clear pattern of increasing $\alpha$ as we increase the magnitude of the financing costs. Indeed, while we cannot reject that $\alpha=0$ when $b_{1}=0$, this hypothesis is rejected for most of the other parameter configurations.

We also report the implications of financing costs for the raw moments of investment returns and their correlation with market returns. While both the mean and the variance of investment returns are not changed by much as $b_{1}$ increases (at least initially), the correlation with stock returns lowers significantly. Since the overall performance of a factor model hinges on its covariance structure with returns, it is not surprising that financing costs are not important for the construction of the pricing kernel as documented in Table $2 .^{31}$

\section{Robustness}

This section examines the robustness of our results by exploring several alternatives to our benchmark approach. Specifically we study the effects of using alternative moment conditions, consider several alternative measures of the financing premium, non-linear pricing kernels and, finally, look at alternative macroeconomic data.

\subsection{Alternative Sets of Moment Conditions}

Many authors interpret the cross-sectional variation in the Fama and French (1993) size and book-to-market portfolio returns as proxies for financial distress. Panel A in Table 5 investigate this possibility by using our model to price the 25 Fama and French (1993) portfolio returns. Specifically, the unconditional model uses the excess returns of portfolios $11,13,15,23,31,33,35,43,51,53,55$ of the Fama and French (1993) 25 portfolios, one investment excess return (over real corporate bond return), and real corporate bond return

\footnotetext{
${ }^{31}$ An alternative way of representing the impact of financing constraints is to compare their effect on the pricing kernels with the Hansen-Jagannathan (1991) bounds. Here, increasing $b_{1}$ has the effect of moving the estimated kernels farther way from the bounds.
} 
(13 moment conditions). ${ }^{32}$ The conditional and scaled model use excess returns of FamaFrench portfolio 11, 15, 51, and 55, scaled by instruments, excess investment return (over corporate bond return) and the real corporate bond return (16 moment conditions). The results show that, even here however, the estimated value of $b_{1}$ is again either negative or zero.

In addition, several studies on firm financing constraints emphasize that they are more likely to be detected when looking only at the behavior of small firms. An easy way to assess the model's implications for different firms is to test the moment conditions (23) for portfolios of small firms only. Panel B of Table 5 reports GMM estimates and tests using small firm portfolios in the moment conditions. Specifically, the unconditional model uses the excess returns of $11,12,13,14,15,21,22,23,24$, and 25 of the Fama and French 25 portfolios, one investment excess return (over real corporate bond return), and real corporate bond return (12 moment conditions). The conditional and scaled model use excess returns of Fama-French portfolios 11, 12, 13, and 15, scaled by instruments, excess investment return (over corporate bond return) and the real corporate bond return (16 moment conditions). Nevertheless, our basic conclusions also seem to hold for this subset of firms.

\subsection{Alternative Measure of the Financing Premium}

As we have argued above in Section 4.2, our results are not sensitive to the specific measure of the financing premium, as long as it has the same countercyclical property of the default premium. Table 6 confirms our results by using an alternative measure of the default premium - the spread between the yields on Baa bonds and those on ten year government notes.

\footnotetext{
${ }^{32}$ Following popular convention, the first digit denotes the size group and the second digit denotes the book-to-market group, both of which are in ascending order. Thus, portfolio 15 is formed by the intersection of smallest size and highest book-to-market ratio.
} 
Table 5 : GMM Estimates and Tests with Alternative Moment Conditions

\begin{tabular}{|c|c|c|c|c|c|c|c|c|c|c|c|c|}
\hline & \multicolumn{12}{|c|}{ Panel A: Fama-French Portfolios } \\
\hline & \multicolumn{6}{|c|}{ Unrestricted Model } & \multicolumn{6}{|c|}{ Restricted Model } \\
\hline & \multicolumn{2}{|c|}{ Unconditional } & \multicolumn{2}{|c|}{ Conditional } & \multirow{2}{*}{\multicolumn{2}{|c|}{$\frac{\text { Scaled Factor }}{\text { Paramete }}$}} & \multicolumn{2}{|c|}{ Unconditional } & \multicolumn{2}{|c|}{ Conditional } & \multicolumn{2}{|c|}{ Scaled Facto } \\
\hline & & & & & & & & & & & & \\
\hline$a$ & 0.00 & & 1.35 & $(0.10)$ & 0.00 & & 13.79 & $(1.87)$ & 34.40 & $(2.86)$ & 22.23 & $(2.37)$ \\
\hline$b$ & -0.13 & $(-1.82)$ & -0.26 & $(-2.23)$ & -0.22 & $\begin{array}{l}(-1.62) \\
J_{T} \text { Test }\end{array}$ & 0.00 & & 0.00 & & 0.00 & \\
\hline$\chi^{2}$ & 33.57 & & 25.47 & & 16.10 & & 48.09 & & 24.83 & & 12.93 & \\
\hline$p$ & 0.00 & & 0.01 & & 0.02 & & 0.00 & & 0.01 & & 0.07 & \\
\hline \multicolumn{13}{|c|}{ Wald Test $(b=0)$} \\
\hline \multirow{5}{*}{$\begin{array}{c}\chi_{(1)}^{2} \\
p\end{array}$} & 4.41 & & 13.60 & & 3.95 & & & & & & & \\
\hline & 0.04 & & 0.00 & & 0.05 & & & & & & & \\
\hline & \multicolumn{12}{|c|}{ Panel B: Small Firm Deciles } \\
\hline & \multicolumn{6}{|c|}{ Unrestricted Model } & \multicolumn{6}{|c|}{ Restricted Model } \\
\hline & Uncor & ditional & Cond & itional & Scales & Factor & Uncon & ditional & Cond & tional & Scaled & Factor \\
\hline \multicolumn{13}{|c|}{ Parameters } \\
\hline$a$ & 1.26 & $(0.55)$ & 14.40 & $(1.80)$ & 2.21 & $(0.41)$ & 3.14 & $(1.18)$ & 37.52 & $(2.45)$ & 2.56 & $(0.74)$ \\
\hline$b$ & -0.05 & $(-1.24)$ & -0.18 & $(-2.42)$ & -0.11 & $\begin{array}{l}(-0.58) \\
J_{T} \text { Test }\end{array}$ & 0.00 & & 0.00 & & 0.00 & \\
\hline$\chi^{2}$ & 32.73 & & 20.17 & & 9.99 & & 35.22 & & 18.08 & & 9.89 & \\
\hline$p$ & 0.00 & & 0.04 & & 0.19 & & 0.00 & & 0.08 & & 0.19 & \\
\hline \multicolumn{13}{|c|}{ Wald Test $(b=0)$} \\
\hline$\chi_{(1)}^{2}$ & 2.19 & & 6.60 & & 2.20 & & & & & & & \\
\hline$p$ & 0.14 & & 0.01 & & 0.14 & & & & & & & \\
\hline
\end{tabular}

Panel A reports GMM estimates and tests using Fama-French 25 portfolios in the moment conditions. Specifically, the unconditional model uses the excess returns of portfolios 11, 13, 15, 23, 31, 33, 35, 43, 51, 53, 55 of the Fama and French (1993) 25 portfolios, one investment excess return (over real corporate bond return), and real corporate bond return (13 moment conditions). The Fama-French portfolios are numbered such that the first digit denotes the size group and the second digit denotes the book-to-market group, both of which are in ascending order. The conditional and scaled model use excess returns of Fama-French portfolio $11,15,51$, and 55, scaled by instruments, excess investment return and the real corporate bond return (16 moment conditions). Panel B reports GMM estimates and tests using small firm portfolios. Specifically, the unconditional model uses the excess returns of 11, 12, 13, 14, 15, 21, 22, 23, 24, and 25 of the Fama and French 25 portfolios, one investment excess return, and real corporate bond return (12 moment conditions). The conditional and scaled model use excess returns of Fama-French portfolios 11, 12, 13, and 15, scaled by instruments, excess investment return and the real corporate bond return (16 moment conditions). We report the estimates for $a$ and $b_{1}$, the $\chi^{2}$ statistic and corresponding $p$-value for the $J_{T}$ test on over-identification, and $\chi^{2}$ statistic and $p$-value of the Wald test on the null hypothesis that $b_{1}=0 . t$-statistics are reported in parentheses to the right of parameter estimates. The pricing kernels are the same as in the benchmark case reported in Table 2. 
Table 6 : GMM Estimates and Tests with Alternative Default Premium Measured As Yield Spread Between Baa and Ten-year Treasury Bond

\begin{tabular}{|c|c|c|c|c|c|c|c|c|c|c|c|c|}
\hline & \multicolumn{12}{|c|}{ Panel A: Size Deciles } \\
\hline & \multicolumn{6}{|c|}{ Unrestricted Model } & \multicolumn{6}{|c|}{ Restricted Model } \\
\hline & \multicolumn{2}{|c|}{ Unconditional } & \multicolumn{2}{|c|}{ Conditional } & \multicolumn{2}{|c|}{ Scaled Factor } & \multicolumn{2}{|c|}{ Unconditional } & \multicolumn{2}{|c|}{ Conditional } & \multicolumn{2}{|c|}{ Scaled Factor } \\
\hline \multicolumn{13}{|c|}{ Parameters } \\
\hline$a$ & 0.00 & & 7.48 & $(1.74)$ & 4.61 & $(0.81)$ & 1.44 & $(1.03)$ & 8.71 & $(3.03)$ & 6.33 & $(1.63)$ \\
\hline$b$ & -0.03 & $(-0.83)$ & -0.10 & $(-2.26)$ & -0.10 & $\begin{array}{l}(-1.85) \\
J_{T} \text { Test }\end{array}$ & 0.00 & & 0.00 & & 0.00 & \\
\hline$\chi^{2}$ & 7.69 & & 11.63 & & 6.85 & & 10.54 & & 18.12 & & 10.50 & \\
\hline$p$ & 0.36 & & 0.39 & & 0.44 & & 0.16 & & 0.08 & & 0.16 & \\
\hline \multicolumn{13}{|c|}{ Wald Test $(b=0)$} \\
\hline$\chi_{(1)}^{2}$ & 3.55 & & 8.88 & & 6.01 & & & & & & & \\
\hline \multirow[t]{4}{*}{$p$} & 0.06 & & 0.00 & & 0.01 & & & & & & & \\
\hline & \multicolumn{12}{|c|}{ Panel B: Fama-French Portfolios } \\
\hline & \multicolumn{6}{|c|}{ Unrestricted Model } & \multicolumn{6}{|c|}{ Restricted Model } \\
\hline & Uncor & ditional & Cond & tional & Scale & Factor & Uncon & litional & Cond & itional & Scaled & Factor \\
\hline \multicolumn{13}{|c|}{ Parameters } \\
\hline$a$ & 0.00 & & 3.35 & $(0.17)$ & 0.00 & & 13.53 & $(1.96)$ & 34.81 & $(3.43)$ & 22.21 & $(2.49)$ \\
\hline$b$ & -0.09 & $(-1.74)$ & -0.22 & $(-2.09)$ & -0.17 & $\begin{array}{l}(-1.07) \\
J_{T} \text { Test }\end{array}$ & 0.00 & & 0.00 & & 0.00 & \\
\hline$\chi^{2}$ & 28.77 & & 21.60 & & 8.53 & & 47.52 & & 24.72 & & 13.28 & \\
\hline$p$ & 0.00 & & 0.03 & & 0.29 & & 0.00 & & 0.01 & & 0.07 & \\
\hline \multicolumn{13}{|c|}{ Wald Test $(b=0)$} \\
\hline$\chi_{(1)}^{2}$ & 5.63 & & 10.52 & & 2.89 & & & & & & & \\
\hline$p$ & 0.02 & & 0.00 & & 0.09 & & & & & & & \\
\hline
\end{tabular}

This table reports GMM estimates and tests of both the unrestricted and restricted models with alternative measure of external financing premium. In contrast to the benchmark case reported in Table 2 where default premium $d_{t}$ is defined as the difference between yields of Baa and Aaa bonds, here $d_{t}$ is the difference between yields of Baa and long-term government bonds. Panel A reports GMM estimates and tests using 10 CRSP size deciles in the moment conditions as in the benchmark Table tb:gmmBench. Panel B reports GMM estimates and tests using Fama-French portfolios in the moment conditions as in Panel A of Table 5. We report the estimates for $a$ and $b_{1}$, the $\chi^{2}$ statistic and corresponding $p$-value for the $J_{T}$ test on overidentification, and $\chi^{2}$ statistic and $p$-value of the Wald test on the null hypothesis that $b_{1}=0 . t$-statistics are reported in parentheses to the right of parameter estimates. The pricing kernels are the same as in the benchmark case reported in Table 2 . 
As discussed above, the financing premium can also be represented as an increasing function of the external-finance-to-capital ratio, $X / K$. This representation has the advantage of generality, since it holds regardless of the exact form of external finance used. Accordingly, Table 7 shows the results of using $X / K$ as the common factor in the financing premium. The results confirm the robustness of our findings under this more general representation. Table 8 then combines both the default premium and the amount of external finance by representing the financing premium as $b\left(S_{t}\right)\left(X_{t} / K_{t}\right)$. Although this ad-hoc representation is not formally justified, it does allow for the possibility of measurement error in either measure. Again however, Table 8 confirms that this modification has a only negligible impact on our results.

Finally, we also look at two more elaborate measures of financing constraints. One is the aggregate default likelihood measure constructed in Vassalou and Xing (2002). The other one is the common factor of financing constraints constructed in Lamont, Polk, and Saa-Requejo (2001).

Vassalou and Xing (2002) use firm-level equity data to estimate default likelihood indicators for individual firms following the contingent claims methodology of Merton (1974). These indicators are nonlinear functions of the default probabilities of the firms. The aggregate default likelihood measure is then defined as a simple average of the default likelihood indicators of all firms. Vassalou and Xing (2002) show that this aggregate default measure varies greatly with the business cycle and increases substantially during recessions. ${ }^{33}$ Tables 9 reports our GMM results for this case. As before, we find that $b_{1}$ is mostly negative in the unrestricted model and mostly zero in the restricted model. This is not surprising, since the aggregate default measure is also quite countercyclical.

\footnotetext{
${ }^{33}$ We thank Maria Vassalou for providing us with the series of aggregate default measure. This default measure is monthly and goes from January 1971 to December of 1999 . We construct the corresponding quarterly measure by averaging the likelihoods of the three months within a given quarter.
} 
Table 7 : GMM Estimates and Tests with Alternative External Finance Premium Measured As a Linear Function of External-Finance-Capital Ratio

\begin{tabular}{|c|c|c|c|c|c|c|c|c|c|c|c|c|}
\hline & \multicolumn{12}{|c|}{ Panel A: Size Deciles } \\
\hline & \multicolumn{6}{|c|}{ Unrestricted Model } & \multicolumn{6}{|c|}{ Restricted Model } \\
\hline & \multicolumn{2}{|c|}{ Unconditional } & \multicolumn{2}{|c|}{ Conditional } & \multicolumn{2}{|c|}{ Scaled Factor } & \multicolumn{2}{|c|}{ Unconditional } & \multicolumn{2}{|c|}{ Conditional } & \multicolumn{2}{|c|}{ Scaled Factor } \\
\hline \multicolumn{13}{|c|}{ Parameters } \\
\hline$a$ & 0.26 & $(0.33)$ & 0.77 & $(0.56)$ & 0.00 & & 0.00 & & 2.90 & $(1.00)$ & 25.00 & $(0.26)$ \\
\hline$b$ & -0.66 & $(-1.26)$ & -0.70 & $(-3.06)$ & -2.81 & $\begin{array}{l}(-1.75) \\
J_{T} \text { Tes }\end{array}$ & 0.00 & & 0.00 & & 0.25 & $(0.03)$ \\
\hline$\chi^{2}$ & 21.37 & & 34.64 & & 2.09 & & 43.69 & & 41.75 & & 8.44 & \\
\hline$p$ & 0.00 & & 0.00 & & 0.95 & & 0.00 & & 0.00 & & 0.30 & \\
\hline \multicolumn{13}{|c|}{ Wald Test $(b=0)$} \\
\hline$\chi_{(1)}^{2}$ & 1.54 & & 16.25 & & 12.89 & & & & & & 0.03 & \\
\hline$p$ & 0.21 & & 0.00 & & 0.00 & & & & & & 0.87 & \\
\hline & \multicolumn{12}{|c|}{ Panel B: Fama-French Portfolios } \\
\hline & \multicolumn{6}{|c|}{ Unrestricted Model } & \multicolumn{6}{|c|}{ Restricted Model } \\
\hline & Uncon & litional & Cond & itional & Scaled & Factor & Uncon & ditional & Cond & itional & Scaled & Factor \\
\hline \multicolumn{13}{|c|}{ Parameters } \\
\hline$a$ & 3.47 & $(1.84)$ & 53.15 & $(2.59)$ & 3.21 & $(0.81)$ & 3.47 & $(1.84)$ & 46.51 & $(2.75)$ & 2.01 & $(0.80)$ \\
\hline$b$ & 0.25 & $(0.36)$ & -0.59 & $(-0.11)$ & -0.86 & $\begin{array}{l}(-0.42) \\
J_{T} \text { Tes }\end{array}$ & 0.25 & $(0.36)$ & 0.00 & & 0.00 & \\
\hline$\chi^{2}$ & 36.87 & & 29.06 & & 8.97 & & 36.87 & & 29.64 & & 9.41 & \\
\hline$p$ & 0.00 & & 0.00 & & 0.26 & & 0.00 & & 0.00 & & 0.22 & \\
\hline \multicolumn{13}{|c|}{ Wald Test $(b=0)$} \\
\hline$\chi_{(1)}^{2}$ & 1.77 & & 0.03 & & 0.11 & & 1.77 & & & & & \\
\hline$p$ & 0.18 & & 0.87 & & 0.75 & & 0.18 & & & & & \\
\hline
\end{tabular}

This table reports GMM estimates and tests of both the unrestricted and restricted models with alternative measure of external financing premium. In contrast to the benchmark case reported in Table 2 where external financing premium is assumed to be $b_{0}+b_{1} d_{t}$ and where the default premium, $d_{t}$, is defined as the difference between yields of Baa and Aaa bonds, here the external financing premium is assumed to be $b_{0}+b_{1}\left(X_{t} / K_{t}\right)$ where $X_{t}$ denotes the amount of external finance. Panel A reports GMM estimates and tests using 10 CRSP size deciles in the moment conditions as in the benchmark Table 2. Panel B reports GMM estimates and tests using Fama-French portfolios in the moment conditions as in Panel A of Table 5. We report the estimates for $a$ and $b_{1}$, the $\chi^{2}$ statistic and corresponding $p$-value for the $J_{T}$ test on over-identification, and $\chi^{2}$ statistic and $p$-value of the Wald test on the null hypothesis that $b_{1}=0 . t$-statistics are reported in parentheses to the right of parameter estimates. The pricing kernels are the same as in the benchmark case reported in Table 2 . 
Table 8 : GMM Estimates and Tests using both the Default Premium and the External Finance to Size Ratio

\begin{tabular}{|c|c|c|c|c|c|c|c|c|c|c|c|c|}
\hline & \multicolumn{12}{|c|}{ Panel A: Size Deciles } \\
\hline & \multicolumn{6}{|c|}{ Unrestricted Model } & \multicolumn{6}{|c|}{ Restricted Model } \\
\hline & \multicolumn{2}{|c|}{ Unconditional } & \multicolumn{2}{|c|}{ Conditional } & \multicolumn{2}{|c|}{ Scaled Factor } & \multicolumn{2}{|c|}{ Unconditional } & \multicolumn{2}{|c|}{ Conditional } & \multicolumn{2}{|c|}{ Scaled Facto } \\
\hline \multicolumn{13}{|c|}{ Parameters } \\
\hline$a$ & 0.00 & & 8.00 & $(1.58)$ & 7.75 & $(1.57)$ & 3.55 & $(1.74)$ & 12.44 & $(3.79)$ & 9.04 & $(1.68)$ \\
\hline$b$ & -0.23 & $(-2.04)$ & -0.34 & $(-2.44)$ & -0.25 & $\begin{array}{l}(-1.10) \\
J_{T} \text { Test }\end{array}$ & 0.00 & & 0.00 & & 0.00 & \\
\hline$\chi^{2}$ & 5.16 & & 11.50 & & 7.25 & & 11.82 & & 18.03 & & 9.82 & \\
\hline$p$ & 0.64 & & 0.40 & & 0.40 & & 0.11 & & 0.08 & & 0.2 & \\
\hline \multicolumn{13}{|c|}{ Wald Test $(b=0)$} \\
\hline$\chi_{(1)}^{2}$ & 3.61 & & 9.23 & & 4.12 & & & & & & & \\
\hline \multirow[t]{4}{*}{$p$} & 0.06 & & 0.00 & & 0.04 & & & & & & & \\
\hline & \multicolumn{12}{|c|}{ Panel B: Fama-French Portfolios } \\
\hline & \multicolumn{6}{|c|}{ Unrestricted Model } & \multicolumn{6}{|c|}{ Restricted Model } \\
\hline & Uncon & ditional & Cond & itional & Scalec & Factor & Uncon & ditional & Cond & tional & Scaled & Factor \\
\hline \multicolumn{13}{|c|}{ Parameters } \\
\hline$a$ & 0.00 & & 17.11 & $(1.15)$ & 14.42 & $(1.35)$ & 19.18 & $(1.95)$ & 36.33 & $(2.70)$ & 25.10 & $(2.68)$ \\
\hline$b$ & -0.30 & $(-2.62)$ & -0.43 & $(-1.23)$ & -0.31 & $\begin{array}{l}(-1.02) \\
J_{T} \text { Test }\end{array}$ & 0.00 & & 0.00 & & 0.00 & \\
\hline$\chi^{2}$ & 27.00 & & 22.01 & & 15.34 & & 52.08 & & 25.68 & & 12.61 & \\
\hline$p$ & 0.00 & & 0.02 & & 0.03 & & 0.00 & & 0.01 & & 0.08 & \\
\hline \multicolumn{13}{|c|}{ Wald Test $(b=0)$} \\
\hline$\chi_{(1)}^{2}$ & 4.35 & & 7.27 & & 1.97 & & & & & & & \\
\hline$p$ & 0.04 & & 0.01 & & 0.16 & & & & & & & \\
\hline
\end{tabular}

This table reports GMM estimates and tests of both the unrestricted and restricted models with a financing premium equal to $b\left(S_{t}\right) X_{t} / K_{t}$ where $K_{t}$ denotes the capital stock. Panel A reports GMM estimates and tests using 10 CRSP size deciles in the moment conditions as in the benchmark Table 2. Panel B reports GMM estimates and tests using Fama-French portfolios in the moment conditions as in Panel A of Table 5 . We report the estimates for $a$ and $b_{1}$, the $\chi^{2}$ statistic and corresponding $p$-value for the $J_{T}$ test on overidentification, and $\chi^{2}$ statistic and $p$-value of the Wald test on the null hypothesis that $b_{1}=0 . t$-statistics are reported in parentheses to the right of parameter estimates. The pricing kernels are the same as in the benchmark case reported in Table 2 . 
The common factor of financial constraints constructed in Lamont, Polk, and Saa-Requejo (2001) is the return spread between more financially constrained firms and less constrained firms, where the degree of being constrained is quantified using the methodology of Kaplan and Zingales (1997). This factor is also more related to external equity-financing premium, since it is constructed using data on equity returns. ${ }^{34}$ Table 10 also confirms our earlier intuition. In this case most of the estimates of $b_{1}$ are not significantly different from zero. Again, this is not surprising since the common factor of financing constraint does not seem to covary with credit conditions or business cycles, as documented in Lamont, Polk, and Saa-Requejo (2001).

\subsection{Alternative Macroeconomic Series}

Table 11 shows the effects of using alternative data in the construction of the investment returns. Panel A reports the results of using after tax profits in the construction of investment returns, while Panel B reports similar results when the overall macroeconomic aggregate profit series is used. In either case it is easy to see that our results are very similar to those in Table 2.

\subsection{Non-Linear Pricing Kernels}

The use of a linear factor representation may be restrictive, and several alternative approaches modelling nonlinear pricing kernels have been recently advanced in the literature. ${ }^{35}$ We explore this possibility by re-estimating the moment conditions using several nonlinear pricing kernels. Here, we consider examples where the pricing kernel is quadratic in either $R^{I}$ alone or in both $R^{I}$ and $R^{B}$. As Table 12 shows, none of these cases changes

\footnotetext{
${ }^{34}$ We thank Christopher Polk for providing us with the series of financing constraint common factor. The series is monthly and goes from July of 1968 to December of 1997. We construct the corresponding quarterly factor by time aggregation.

${ }^{35}$ E.g., Bansal and Vishwanathan (1993), Chapman (1997), and Brandt and Yaron (2001).
} 
Table 9 : GMM Estimates and Tests with Alternative External Finance Premium Measured As a Linear Function of Aggregate Default Measure

\begin{tabular}{|c|c|c|c|c|c|c|c|c|c|c|c|}
\hline & \multicolumn{11}{|c|}{ Panel A: Size Deciles } \\
\hline & \multicolumn{5}{|c|}{ Unrestricted Model } & \multicolumn{6}{|c|}{ Restricted Model } \\
\hline & Unconditional & \multicolumn{2}{|c|}{ Conditional } & \multicolumn{2}{|c|}{ Scaled Factor } & \multicolumn{2}{|c|}{ Unconditional } & \multicolumn{2}{|c|}{ Conditional } & \multicolumn{2}{|c|}{ Scaled Facto } \\
\hline \multicolumn{12}{|c|}{ Parameters } \\
\hline$a$ & $4.59 \quad(0.65)$ & 1.50 & $(1.00)$ & 1.17 & $(0.34)$ & 20.00 & $(0.49)$ & 3.79 & $(1.16)$ & 0.00 & \\
\hline$b_{1}$ & $-0.02 \quad(-1.78)$ & -0.02 & $(-5.48)$ & -0.02 & $\begin{array}{l}(-1.96) \\
J_{T} \text { Test }\end{array}$ & 0.00 & & 0.00 & & 0.02 & $(4.21)$ \\
\hline$\chi^{2}$ & 4.32 & 26.10 & & 5.72 & & 13.80 & & 62.65 & & 10.32 & \\
\hline$p$ & 0.74 & 0.01 & & 0.57 & & 0.05 & & 0.00 & & 0.17 & \\
\hline \multicolumn{12}{|c|}{ Wald Test $\left(b_{1}=0\right)$} \\
\hline$\chi_{(1)}^{2}$ & 2.24 & 35.07 & & 1.27 & & & & & & 13.45 & \\
\hline$p$ & 0.13 & 0.00 & & 0.26 & & & & & & 0.00 & \\
\hline & \multicolumn{11}{|c|}{ Panel B: Fama-French Portfolios } \\
\hline & \multicolumn{5}{|c|}{ Unrestricted Model } & \multicolumn{6}{|c|}{ Restricted Model } \\
\hline & Unconditional & Cond & tional & Scalec & Factor & Uncon & itional & Cond & itional & Scaled & Factor \\
\hline \multicolumn{12}{|c|}{ Parameters } \\
\hline$a$ & $35.70 \quad(1.14)$ & 20.00 & $(0.55)$ & 4.89 & $(0.72)$ & 35.70 & (1.14) & 20.00 & $(0.55)$ & 6.29 & $(0.68)$ \\
\hline$b_{1}$ & 0.00 & 0.06 & $(0.95)$ & -0.01 & $\begin{array}{l}(-0.32) \\
J_{T} \text { Test }\end{array}$ & 0.00 & & 0.06 & $(0.95)$ & 0.00 & \\
\hline$\chi^{2}$ & 13.70 & 43.82 & & 11.14 & & 47.52 & & 43.82 & & 11.94 & \\
\hline$p$ & 0.06 & 0.00 & & 0.13 & & 0.00 & & 0.00 & & 0.10 & \\
\hline \multicolumn{12}{|c|}{ Wald Test $\left(b_{1}=0\right)$} \\
\hline$\chi_{(1)}^{2}$ & & 2.77 & & 0.17 & & & & 2.77 & & & \\
\hline$p$ & & 0.10 & & 0.68 & & & & 0.10 & & & \\
\hline
\end{tabular}

This table reports GMM estimates and tests of both the unrestricted and restricted models with alternative measure of external financing premium. In contrast to the benchmark case reported in Table 2 where external financing premium is a liner function of default premium, here it is a linear function of the aggregate default likelihood indicator constructed in Vassalou and Xing (2002). Panel A reports GMM estimates and tests using 10 CRSP size deciles in the moment conditions as in the benchmark Table 2. Panel B reports GMM estimates and tests using Fama-French portfolios in the moment conditions as in Panel A of Table 5. We report the estimates for $a$ and $b_{1}$, the $\chi^{2}$ statistic and corresponding $p$-value for the $J_{T}$ test on over-identification, and $\chi^{2}$ statistic and $p$-value of the Wald test on the null hypothesis that $b_{1}=0 . t$-statistics are reported in parentheses to the right of parameter estimates. The pricing kernels are the same as in the benchmark case reported in Table 2. 
Table 10 : GMM Estimates and Tests with Alternative External Finance Premium Measured As a Linear Function of the Common Factor of Financing Constraints

\begin{tabular}{|c|c|c|c|c|c|c|c|c|c|c|c|c|}
\hline & \multicolumn{12}{|c|}{ Panel A: Size Deciles } \\
\hline & \multicolumn{6}{|c|}{ Unrestricted Model } & \multicolumn{6}{|c|}{ Restricted Model } \\
\hline & \multicolumn{2}{|c|}{ Unconditional } & \multicolumn{2}{|c|}{ Conditional } & \multicolumn{2}{|c|}{ Scaled Factor } & \multicolumn{2}{|c|}{ Unconditional } & \multicolumn{2}{|c|}{ Conditional } & \multicolumn{2}{|c|}{ Scaled Facto } \\
\hline \multicolumn{13}{|c|}{ Parameters } \\
\hline$a$ & 0.00 & & 0.00 & & 0.00 & & 50.00 & $(0.30)$ & 4.86 & $(1.16)$ & 0.00 & \\
\hline$b_{1}$ & -0.59 & $(-0.77)$ & -0.29 & $(-2.69)$ & 0.21 & $\begin{array}{l}(1.80) \\
J_{T} \text { Test }\end{array}$ & 0.60 & $(0.55)$ & 0.00 & & 0.21 & $(1.79)$ \\
\hline$\chi^{2}$ & 61.06 & & 26.18 & & 5.35 & & 21.18 & & 74.92 & & 5.29 & \\
\hline$p$ & 0.00 & & 0.01 & & 0.62 & & 0.00 & & 0.00 & & 0.62 & \\
\hline \multicolumn{13}{|c|}{ Wald Test $\left(b_{1}=0\right)$} \\
\hline$\chi_{(1)}^{2}$ & 1.05 & & 23.44 & & 2.77 & & 0.05 & & & & 2.77 & \\
\hline \multirow[t]{4}{*}{$p$} & 0.31 & & 0.00 & & 0.10 & & 0.83 & & & & 0.10 & \\
\hline & \multicolumn{12}{|c|}{ Panel B: Fama-French Portfolios } \\
\hline & \multicolumn{6}{|c|}{ Unrestricted Model } & \multicolumn{6}{|c|}{ Restricted Model } \\
\hline & Uncon & ditional & Cond & tional & Scalec & Factor & Uncon & litional & Cond & itional & Scaled & Factor \\
\hline \multicolumn{13}{|c|}{ Parameters } \\
\hline$a$ & 21.65 & $(0.76)$ & 3.67 & $(0.87)$ & 12.20 & $(0.89)$ & 21.64 & $(0.76)$ & 3.66 & $(0.87)$ & 12.20 & $(0.89)$ \\
\hline$b_{1}$ & 0.68 & $(1.23)$ & 0.00 & & 0.06 & $\begin{array}{l}(0.34) \\
J_{T} \text { Test }\end{array}$ & 0.68 & $(1.23)$ & 0.00 & & 0.06 & $(0.34)$ \\
\hline$\chi^{2}$ & 16.16 & & 91.63 & & 6.11 & & 16.16 & & 91.63 & & 6.11 & \\
\hline$p$ & 0.02 & & 0.00 & & 0.53 & & 0.02 & & 0.00 & & 0.53 & \\
\hline \multicolumn{13}{|c|}{ Wald Test $\left(b_{1}=0\right)$} \\
\hline$\chi_{(1)}^{2}$ & 2.44 & & & & 0.16 & & 2.44 & & & & 0.16 & \\
\hline$p$ & 0.12 & & & & 0.67 & & 0.12 & & & & 0.67 & \\
\hline
\end{tabular}

This table reports GMM estimates and tests of both the unrestricted and restricted models with alternative measure of external financing premium. In contrast to the benchmark case reported in Table 2 where external financing premium is a liner function of default premium, here it is a linear function of the common factor of financing constraints constructed by Lamont, Polk, and Saa-Requejo (2001). Panel A reports GMM estimates and tests using $10 \mathrm{CRSP}$ size deciles in the moment conditions as in the benchmark Table 2. Panel B reports GMM estimates and tests using Fama-French portfolios in the moment conditions as in Panel A of Table 5. We report the estimates for $a$ and $b_{1}$, the $\chi^{2}$ statistic and corresponding $p$-value for the $J_{T}$ test on over-identification, and $\chi^{2}$ statistic and $p$-value of the Wald test on the null hypothesis that $b_{1}=0$. $t$-statistics are reported in parentheses to the right of parameter estimates. The pricing kernels are the same as in the benchmark case reported in Table 2. 
Table 11 : GMM Estimates and Tests with Alternative Measures of Profits

\begin{tabular}{|c|c|c|c|c|c|c|c|c|c|c|c|}
\hline & \multicolumn{11}{|c|}{ Panel A: Nonfinancial After Tax } \\
\hline & \multicolumn{6}{|c|}{ Unrestricted Model } & \multicolumn{5}{|c|}{ Restricted Model } \\
\hline & \multicolumn{2}{|c|}{ Unconditional } & \multicolumn{2}{|c|}{ Conditional } & \multirow{2}{*}{\multicolumn{2}{|c|}{$\frac{\text { Scaled Factor }}{\text { Paramete }}$}} & \multicolumn{2}{|c|}{ Unconditional } & \multicolumn{2}{|c|}{ Conditional } & Scaled Facto \\
\hline & & & & & & & & & & & \\
\hline$a$ & 0.79 & $(0.65)$ & 4.17 & $(0.84)$ & 2.77 & $(0.62)$ & 2.06 & $(1.92)$ & 5.81 & $(2.49)$ & $1.65 \quad(0.87)$ \\
\hline \multirow[t]{2}{*}{$b$} & -0.04 & $(-1.20)$ & -0.17 & $(-3.84)$ & -0.12 & $(-2.21)$ & 0.00 & & 0.00 & & 0.00 \\
\hline & & & & & & $J_{T}$ Test & & & & & \\
\hline$\chi^{2}$ & 4.70 & & 8.78 & & 5.93 & & 5.99 & & 25.71 & & 8.74 \\
\hline$p$ & 0.70 & & 0.64 & & 0.55 & & 0.54 & & 0.01 & & 0.27 \\
\hline \multicolumn{12}{|c|}{ Wald Test $(b=0)$} \\
\hline \multirow{5}{*}{$\begin{array}{c}\chi_{(1)}^{2} \\
p\end{array}$} & 2.42 & & 12.60 & & 6.38 & & & & & & \\
\hline & 0.12 & & 0.00 & & 0.01 & & & & & & \\
\hline & \multicolumn{11}{|c|}{ Panel B: Aggregate Profits } \\
\hline & \multicolumn{6}{|c|}{ Unrestricted Model } & \multicolumn{5}{|c|}{ Restricted Model } \\
\hline & \multicolumn{2}{|c|}{ Unconditional } & \multicolumn{2}{|c|}{ Conditional } & \multicolumn{2}{|c|}{ Scaled Factor } & \multicolumn{2}{|c|}{ Unconditional } & \multicolumn{2}{|c|}{ Conditional } & Scaled Factor \\
\hline \multicolumn{12}{|c|}{ Parameters } \\
\hline$a$ & 0.00 & & 5.14 & $(0.45)$ & 7.76 & $(1.23)$ & 16.83 & $(0.57)$ & 13.35 & $(2.89)$ & $12.38 \quad(1.67)$ \\
\hline$b$ & -0.14 & $(-0.96)$ & -0.20 & $(-3.18)$ & -0.12 & $(-2.46)$ & 0.00 & & 0.00 & & 0.00 \\
\hline & & & & & & $J_{T}$ Test & & & & & \\
\hline$\chi^{2}$ & 11.12 & & 12.00 & & 13.41 & & 15.18 & & 25.67 & & 12.37 \\
\hline$p$ & 0.13 & & 0.36 & & 0.06 & & 0.03 & & 0.01 & & 0.09 \\
\hline \multicolumn{12}{|c|}{ Wald Test $(b=0)$} \\
\hline$\chi_{(1)}^{2}$ & 4.88 & & 11.63 & & 5.48 & & & & & & \\
\hline$p$ & 0.03 & & 0.00 & & 0.02 & & & & & & \\
\hline
\end{tabular}

This table reports GMM estimates and tests of both the unrestricted and restricted models with alternative measures of profits. In contrast to the benchmark case reported in Table 2 where investment return series are constructed using nonfinancial profits before tax, Panel A reports GMM estimates and tests in which investment return series are constructed using nonfinancial profits after tax and Panel B does the same using aggregate (both financial and nonfinancial) profits. We report the estimates for $a$ and $b_{1}$, the $\chi^{2}$ statistic and corresponding $p$-value for the $J_{T}$ test on over-identification, and $\chi^{2}$ statistic and $p$-value of the Wald test on the null hypothesis that $b_{1}=0 . t$-statistics are reported in parentheses to the right of parameter estimates. The pricing kernel and the set of moment conditions are the same as in the benchmark case reported in Table 2. 
Table 12 : GMM Estimates and Tests with Nonlinear Pricing Kernels

\begin{tabular}{|c|c|c|c|c|c|c|c|c|c|c|c|c|}
\hline & \multicolumn{12}{|c|}{ Panel A: $M=l_{0}+l_{1} R^{I}+l_{2}\left(R^{I}\right)^{2}$} \\
\hline & \multicolumn{6}{|c|}{ Unrestricted Model } & \multicolumn{6}{|c|}{ Restricted Model } \\
\hline & \multicolumn{2}{|c|}{ Unconditional } & \multicolumn{2}{|c|}{ Conditional } & \multicolumn{2}{|c|}{ Scaled Factor } & \multicolumn{2}{|c|}{ Unconditional } & \multicolumn{2}{|c|}{ Conditional } & \multicolumn{2}{|c|}{ Scaled Factor } \\
\hline \multicolumn{13}{|c|}{ Parameters } \\
\hline$a$ & 1.00 & $(0.15)$ & 6.16 & $(1.82)$ & 4.90 & $(1.11)$ & 1.58 & $(1.25)$ & 12.17 & $(4.30)$ & 10.25 & $(2.16)$ \\
\hline$b$ & -0.26 & $(-3.79)$ & -0.19 & $(-3.67)$ & -0.18 & $\begin{array}{l}(-3.31) \\
J_{T} \text { Test }\end{array}$ & 0.00 & & 0.00 & & 0.00 & \\
\hline$\chi^{2}$ & 11.64 & & 8.33 & & 4.21 & & 10.56 & & 17.52 & & 10.00 & \\
\hline$p$ & 0.11 & & 0.68 & & 0.76 & & 0.16 & & 0.09 & & 0.19 & \\
\hline \multicolumn{13}{|c|}{ Wald Test $(b=0)$} \\
\hline$\chi_{(1)}^{2}$ & 1.36 & & 16.72 & & 12.28 & & & & & & & \\
\hline \multirow[t]{4}{*}{$p$} & 0.24 & & 0.00 & & 0.00 & & & & & & & \\
\hline & \multicolumn{12}{|c|}{ Panel B: $M=l_{0}+l_{1} R^{I}+l_{2} R^{B}+l_{3}\left(R^{I}\right)^{2}+l_{4}\left(R^{B}\right)^{2}$} \\
\hline & \multicolumn{6}{|c|}{ Unrestricted Model } & \multicolumn{6}{|c|}{ Restricted Model } \\
\hline & Uncon & litional & Cond & itional & Scaled & Factor & Uncon & litional & Cond & tional & Scaled & Factor \\
\hline \multicolumn{13}{|c|}{ Parameters } \\
\hline$a$ & 1.49 & $(1.48)$ & 8.29 & $(1.25)$ & 3.72 & $(0.68)$ & 2.24 & $(1.97)$ & 9.64 & $(3.14)$ & 19.87 & $(0.20)$ \\
\hline$b$ & -0.03 & $(-1.66)$ & -0.20 & $(-3.34)$ & -0.08 & $\begin{array}{l}(-0.80) \\
J_{T} \text { Test }\end{array}$ & 0.00 & & 0.00 & & 0.00 & \\
\hline$\chi^{2}$ & 1.33 & & 6.56 & & 1.43 & & 4.91 & & 21.52 & & 3.98 & \\
\hline$p$ & 0.93 & & 0.68 & & 0.15 & & 0.43 & & 0.01 & & 0.09 & \\
\hline \multicolumn{13}{|c|}{ Wald Test $(b=0)$} \\
\hline$\chi_{(1)}^{2}$ & 2.35 & & 8.40 & & 4.94 & & & & & & & \\
\hline$p$ & 0.13 & & 0.00 & & 0.03 & & & & & & & \\
\hline
\end{tabular}

This table reports GMM estimates and tests of both the unrestricted and restricted models with alternative specifications of the pricing kernel. In contrast to the benchmark case reported in Table 2 where investment return series are constructed using nonfinancial profits before tax, Panel A reports GMM estimates and tests in which the pricing kernel is: $M=l_{0}+l_{1} R^{I}+l_{2}\left(R^{I}\right)^{2}$ where $R^{I}$ denotes investment return for the unconditional and conditional model and is: $M=l_{0}+l_{1} R^{I}+l_{2}\left(R^{I}\right)^{2}+l_{3}\left(R^{I} \cdot t p\right)+l_{4}\left(R^{I} \cdot d p\right)+l_{5}\left(\left(R^{I}\right)^{2} \cdot t p\right)+$ $l_{6}\left(\left(R^{I}\right)^{2} \cdot d p\right)$ for the scaled factor model. Panel B reports GMM estimates and tests in which the pricing kernel is: $M=l_{0}+l_{1} R^{I}+l_{2} R^{B}+l_{3}\left(R^{I}\right)^{2}+l_{4}\left(R^{B}\right)^{2}$ where $R^{B}$ denotes real corporate bond return for the unconditional and conditional model and is: $M=l_{0}+l_{1} R^{I}+l_{2} R^{B}+l_{3}\left(R^{I}\right)^{2}+l_{4}\left(R^{B}\right)^{2}+l_{5}\left(R^{I} \cdot t p\right)+l_{6}\left(R^{I}\right.$. $d p)+l_{7}\left(R^{B} \cdot t p\right)+l_{8}\left(R^{B} \cdot d p\right)+l_{9}\left(\left(R^{I}\right)^{2} \cdot t p\right)+l_{10}\left(\left(R^{I}\right)^{2} \cdot d p\right)+l_{11}\left(\left(R^{B}\right)^{2} \cdot t p\right)+l_{12}\left(\left(R^{B}\right)^{2} \cdot d p\right)$ for the scaled factor model. We report the estimates for $a$ and $b_{1}$, the $\chi^{2}$ statistic and corresponding $p$-value for the $J_{T}$ test on over-identification, and $\chi^{2}$ statistic and $p$-value of the Wald test on the null hypothesis that $b_{1}=0$. $t$-statistics are reported in parentheses to the right of parameter estimates. The set of moment conditions are the same as in the benchmark case reported in Table 2. The investment return series is constructed from flows of funds accounts using nonfinancial profits before tax. 
our original findings.

\section{Conclusion}

Despite its empirical success, the investment-based asset pricing model (Cochrane (1991, 1996)) has been, until recently, relatively neglected by researchers, in favor of either standard consumption-based or APT-like asset pricing models. This is unfortunate since, by concentrating on optimal firm behavior, this approach holds the promise of endogenously linking firm characteristics with asset returns. Moreover, it also provides a natural way of integrating new developments in the theory of corporate finance into an asset pricing framework.

In this paper we pursue this line of research by incorporating costly external finance in an investment-based asset pricing model and ask whether financing frictions help in pricing the cross-section of expected returns. To avoid specifying the underlying source of these frictions we show that the typical assumptions about the nature of the financing frictions are captured by a simple "financing cost" function, which provides a tractable framework to examine the role of financing frictions in pricing asset returns.

Our empirical findings suggest that the role played by financing frictions, in terms of explaining the cross-section of expected return is fairly negligible. This finding is robust to several alternative formulations of our model, particularly the measures of the financing premium, the specific macroeconomic data used, and the set of returns used in our GMM implementations. We show that our results hold unless the premium on external funds is procyclical, a property not evident in the data and not satisfied by most models of costly external finance.

These findings question whether financing frictions are important for explaining the cross- 
section of expected returns. Moreover, our results also cast doubt on whether financing constraints provide a realistic propagation mechanism in several macroeconomic models.

Strictly speaking however, our methodology applies only to models of costly external finance. Thus, it is also possible to interpret these findings as providing evidence against the popular models of costly external finance, perhaps in favor of alternative views on the nature financing frictions.

A few aspects of our empirical implementation suggest promising directions for future research. First, investment may have an important time-to-build component, and financing procedures may precede the actual investment spending by a quarter or more, leading firms to look at lagged measures of fundamentals when making their decisions. Although our results suggest that this explanation is unlikely to account for the rejection of financing frictions, only an explicit examination of the potential implications of time aggregation can fully address this issue. Second, although financing constraints seem to play no role in determining the systematic component of expected returns in this paper, they may still be fairly important to explain the idiosyncratic component of ex-post firm level returns. Since our model has implications for ex-post returns it can also be used to investigate this issue by looking directly at firm level data as well. 


\section{References}

[1] Abel, B. Andrew, and Janice C. Eberly, 2001, Q Theory Without Adjustment Cost and Cash Flow Effects Without Financing Constraints, Working Paper, The Wharton School at the University of Pennsylvania.

[2] Albuquerque, Rui and Hugo Hopenhayn, Optimal Lending Contracts and Firm Dynamics, Working Paper, University of Rochester, May 2001.

[3] Alvarez, Fernando, and Urban J. Jermann, 2000, Efficiency, Equilibrium, and Asset Pricing With Risk of Default, Econometrica, 68 (4), 775-797.

[4] Almeida, Heitor, and Murillo Campello, 2002, Financial Constraints and InvestmentCash Flow Sensitivities, New Research Directions, Working Paper, Stern School of Business, New York University.

[5] Asquith, Paul, Robert Gertner, and David Sharfstein, 1994, Anatomy of Financial Distress: An Examination of Junk-Bond Issuers, Quarterly Journal of Economics, 109, 625-658.

[6] Berk, Jonathan B., Richard C. Green and Vasant Naik, 1999, Optimal Investment, Growth Options and Security Returns, Journal of Finance, 54, 1513-1607.

[7] Bansal Ravi, and S. Viswanathan, 1993, No Arbitrage and Arbitrage Pricing: A New Approach, Journal of Finance, 48, 1231-1261.

[8] Bernanke, Ben and Mark Gertler, 1989, Agency Costs, Net Worth, and Business Fluctuations, American Economic Review, 79 (1), 14-31.

[9] Bernanke, Ben and Mark Gertler, 1995, Inside the Black Box: The Credit Channel of Monetary Policy transmission, Journal of Economic Perspectives, 9, 27-48.

[10] Bernanke, Ben, Mark Gertler, and Simon Gilchrist, 1996, The Financial Accelerator and the Flight to Quality, Review of Economics and Statistics, 78, 1-15.

[11] Bernanke, Ben, Mark Gertler, and Simon Gilchrist, 1999, The Financial Accelerator in a Quantitative Business Cycle Framework, in Handbook of Macroeconomics, Edited by Michael Woodford and John Taylor, North Holland.

[12] Brandt, Michael W., and Amir Yaron, 2001, Time-Consistent No-Arbitrage Models of the Term Structure, Working Paper, The Wharton School at the University of Pennsylvania. 
[13] Bond, Stephen and Costas Meghir, 1994, Dynamic Investment Models and the Firm's Financial Policy, Review of Economic Studies, 61, 197-222

[14] Carlstrom, Charles T., and Timothy S. Fuerst, 1997, Agency Costs, Net Worth, and Business Fluctuations: A Computable General Equilibrium Analysis, American Economic Review, 87 (5), 893-910.

[15] Chan, K. C., and Nai-fu Chen, 1991, Structural and Return Characteristics of Small and Large Firms, Journal of Finance, 46, 1467-1484.

[16] Chan, K. C., and Nai-fu Chen, and David Hsieh, 1985, An Exploratory Investigation of the Firm Size Effect, Journal of Financial Economics, 14, 451-471.

[17] Chapman, David A., 1997, Approximating the Asset Pricing Kernel, Journal of Finance, $52,1383-1410$.

[18] Chen, Nai-Fu, 1991, Financial Investment Opportunities and the Macroeconomy, Journal of Finance, 46, 2, 529-554.

[19] Chen, Nai-fu, Richard Roll, and Stephen A. Ross, 1986, Economic Forces and the Stock Market, Journal of Business, 59, 383-403.

[20] Clementi, Gian Luca, and Hugo Hopenhayn, 2001, Optimal Lending Contracts and Firms' Survival with Moral Hazard, unpublished manuscript, University of Rochester

[21] Cochrane, John H., 1991, Production-Based Asset Pricing and the Link Between Stock Returns and Economic Fluctuations, Journal of Finance, 46 (1), 209-237.

[22] Cochrane, John H., 1996, A Cross-Sectional Test of an Investment-Based Asset Pricing Model, Journal of Political Economy, 104 (3), 572-621.

[23] Cochrane, John H., 2001, Asset Pricing, Princeton University Press, Princeton, New Jersey.

[24] Cooley, Thomas F., Vincenzo Quadrini, and Ramon Marimon, 2001, Aggregate Consequences of Limited Contract Enforceability, Working Paper, Stern School of Business, New York University.

[25] Constantinides, George M., and Darrell Duffie, 1996, Asset Pricing with Heterogeneous Consumers, Journal of Political Economy, 104 (2), 219-240.

[26] Den Haan, Wouter, Gary Ramey and Joel Watson, 1999, Liquidity Flows and Fragility of Business Enterprises, Working Paper 7057, National Bureau of Economic Research. 
[27] Denis, Davis J., and Diane Denis, 1995, Causes of Financial Distress Following Leveraged Recapitalization, Journal of Financial Economics, 37, 2, 129-157.

[28] Diamond, Douglas W., 1984, Financial Intermediation and Delegated Monitoring, Review of Economic Studies, LI, 393-414.

[29] Fama, Eugene F., 1981, Stock Returns, Real Activity, Inflation, and Money, American Economic Review, 71, 545-565.

[30] Fama, Eugene F., and Michael R. Gibbons, 1982, Inflation, Real Returns and Capital Investment, Journal of Monetary Economics, 9, 297-323.

[31] Fama, Eugene F., and Kenneth R. French, 1993, Common Risk Factors in the Returns on Stocks and Bonds, Journal of Finance, 33, 3-56.

[32] Fama, Eugene F., and Kenneth R. French, 1996, Multifactor Explanations of Asset Pricing Anomalies, Journal of Finance, 51, 55-84.

[33] Gale, Douglas, and Martin Hellwig, 1985, Incentive-Compatible Debt Contracts: The One-Period Problem, Review of Economic Studies, LII, 647-663.

[34] Gilchrist, Simon and Charles Himmelberg, 1998, Investment: Fundamentals and Finance, in NBER Macroeconommics Annual, Ben Bernanke and Julio Rotemberg eds, MIT Press

[35] Gomes, Joao F., 2001, Financing Investment, American Economic Review, 90, 5, 12631285.

[36] Gomes, Joao F., Leonid Kogan, and Lu Zhang, 2002, Equilibrium Cross-Section of Returns, forthcoming, Journal of Political Economy.

[37] Gomes, Joao F., Amir Yaron, and Lu Zhang, 2002, Asset Pricing Implications of Firm's Financing Constraints: Firm Level Evidence, mimeo, The Wharton School at the University of Pennsylvania.

[38] Greenwald, Bruce, Joseph Stiglitz and Andrew Weiss, 1984, Informational Imperfections in the Capital Market and Macroeconomic Fluctuations, American Economic Review, 74, 194-199.

[39] Hansen, Lars Peter, 1982, Large Sample Properties of Generalized Method of Moments Estimation, Econometrica, 50, 1029-1054. 
[40] Hansen, Lars Peter, and S. Richard, 1987, The role of Conditioning Information in Deducing Testable Restrictions Implied by Dynamic Asset Pricing Models, Econometrica, 55, 587-613.

[41] Harrison, Michael and David Kreps, 1979, Martingales and Arbitrage in Multiperiod Securities Markets, Journal of Economic Theory, 20, 381-408.

[42] Harvey, Campbell R., 1989, Forecasts of Economic Growth from the Bond and Stock Markets, Financial Analysts Journal, 45, 5, 38-45.

[43] Jagannathan, Ravi, and Zhenyu Wang, 1996, The Conditional CAPM and the CrossSection of Expected Returns, Journal of Finance, 51, 3-54.

[44] Jermann, Urban J., 1998, Asset Pricing in Production Economies, Journal of Monetary Economics, 41, 257-275.

[45] Kashyap, Anil K., Jeremy C. Stein, and David W. Wilcox, 1993, Monetary Policy and Credit Conditions: Evidence from the Composition of External Finance, American Economic Review, 83, 78-98.

[46] Jensen Michael, and William H. Meckling, 1976, Theory of the Firm: Managerial Behavior, Agency Costs, and Ownership Structure, Journal of Financial Economics, $3,305-360$.

[47] Kaplan, Steven K., Luigi Zingales, 1997, Do Investment Cash-Flow Sensitivities Provide Useful Measures of Financing Constraints?, Quarterly Journal of Economics, CXII, 169216.

[48] Kashyap, Anil K., Owen A. Lamont, and Jeremy C. Stein, 1994, Credit Conditions and the Cyclical Behavior of Inventories, Quarterly Journal of Economics, 109, 565-592.

[49] Kehoe, Timothy, and David K. Levine, 1993, Debt-Constrained Asset Markets, Review of Economic Studies, 60, 868-888.

[50] Keim, Donald B., and Robert F. Stambaugh, 1986, Predicting Returns in the Stock and Bond Market, Journal of Financial Economics, 17, 357-390.

[51] Kiyotaki, Nobuhiro, and John Moore, 1997, Credit Cycles, Journal of Political Economy, 105 (2), 211-248.

[52] Kocherlakota, Narayana R., 1996, Implications of Efficient Risk Sharing Without Commitment, Review of Economic Studies, 63, 595-609. 
[53] Lamont, Owen, Investment Plans and Stock Returns, 2000, Journal of Finance, LV (6), pp. 2719-2745

[54] Lamont, Owen, Christopher Polk and Jesús Saá-Requejo, 2001, Financial Constraints and Stock Returns, forthcoming, Review of Financial Studies.

[55] Lettau, Martin, and Sidney Ludvigson, 2001, Time-Varying Risk Premia and the Cost of Capital: An Alternative Implication of the $Q$ Theory of Investment, Working Paper, New York University.

[56] Li, Qing, Maria Vassalou, and Yuhang Xing, 2001, An Investment Growth Asset Pricing Model, Working Paper, Columbia University.

[57] Myers, Stewart C., 1984, The Capital Structure Puzzle, Journal of Finance, 39 (3), $575-592$.

[58] Myers, Stewart C., and Majluf, N. 1984, Corporate Financing and Investment Decisions When Firms Have Information That Investors Do Not Have, Journal of Financial Economics, 13, 187-222.

[59] Newey, Whitney, and Kenneth West, 1987, Hypothesis Testing with Efficient Method of Moments Estimation, International Economic Review, 28, 777-787.

[60] Opler, Tim, and Sheridan Titman, 1994, Financial Distress and Corporate Performance, Journal of Finance, 49, 1015-1040.

[61] Perez-Quiros, Gabriel, and Allan Timmermann, 2000, Firm Size and Cyclical Variations in Stock Returns, Journal of Finance, LV (3), 1229-1262.

[62] Restoy, Fernando, and G. Michael Rockinger, 1994, On Stock Market Returns and Returns on Investment, Journal of Finance, 49 (2), 543-556.

[63] Stein, Jeremy, 2001, Agency, Information, and Corporate Investment, NBER Working Paper 8342.

[64] Stiglitz, Joseph and Andrew Weiss, 1981, Credit Rationing and Markets with Imperfect Information, American Economic Review, 71, 393-411.

[65] Stock, James H. and Mark W. Watson, 1989, New Indexes of Coincident and Leading Economic Indicators, in NBER Macroeconomics Annual, edited by Oliver J. Blanchard and Stanley Fischer, 352-394. 
[66] Stock, James H. and Mark W. Watson, 1999, Business Cycle Fluctuations in U.S. Macroeconomic Time Series, in Handbook of Macroeconomics, edited by James B. Taylor and Michael Woodford, 1, 3-64.

[67] Townsend, Robert, 1979, Optimal Contracts and Competitive Markets with Costly State Verification, Journal of Economic Theory, 21, 265-293.

[68] Vassalou, Maria, and Yuhang Xing, 2002, Default Risk in Equity Returns, Working Paper, Columbia Businss School.

[69] Williamson, Stephen, 1987, Financial Intermediation, Business Failures, and Real Business Cycles, Journal of Political Economy, 95 (6), 1196-1216.

[70] Zhang Harold, 1997 Endogenous Borrowing Constraints with Incomplete Markets. Journal of Finance, 52, 2187-2205.

[71] Zhang, Lu, 2002, The Value Premium, Working Paper, William E. Simon Graduate School of Business Administration, University of Rochester, Rochester, New York. 


\section{A Proofs}

Proof of Proposition 1. We start by letting

$$
\psi(\bar{A})=\bar{A}(1-\Phi(\bar{A}))+\int_{0}^{\bar{A}} A d \Phi(\bar{A})
$$

denote the expected share of gross profits, $A K$, that accrue to the lender and define

$$
\Upsilon(\bar{A})=\mu \int_{0}^{\bar{A}} A d \Phi(\bar{A})
$$

as the expected monitoring costs to the lender.

Then the optimal contract gives rise to optimal first order conditions

$$
\begin{aligned}
\psi^{\prime}(\bar{A})-\lambda\left[\psi^{\prime}(\bar{A})-\Upsilon^{\prime}(\bar{A})\right] & =0 \\
(1-\psi(\bar{A}))+\lambda[\psi(\bar{A})-\Upsilon(\bar{A})]-R^{f} & =0 \\
{[\psi(\bar{A})-\Upsilon(\bar{A})] K } & =R^{f}(K-F)=R^{f} B
\end{aligned}
$$

which can be solved recursively to obtain a set of functions $\lambda(\bar{A}), \bar{A}\left(R^{f}\right)$ and finally $b=B / K=$ $\eta\left(R^{f}, \bar{A}\right)$.

Since optimal default implies that $R=\bar{A} / b$, it is immediate that

$$
R=\bar{A} / \eta\left(R^{f}, \bar{A}\right)=\rho\left(R^{f}, b\right) \geq R^{f}
$$

and

$$
\rho^{\prime}(b)=\frac{\partial R}{\partial \bar{A}} \frac{\partial \bar{A}}{\partial b}>0
$$

since

$$
\frac{\partial R}{\partial \bar{A}}=\frac{\eta(\bar{A})-\bar{A} \eta^{\prime}(\bar{A})}{\eta(\bar{A})^{2}}=\frac{(1-\mu) \int_{0}^{\bar{A}} A d \Phi(\bar{A})+\mu \bar{A}^{2} d \Phi(\bar{A})}{\eta(\bar{A})^{2}}>0 .
$$

and, since $\Phi(\bar{A})$ has an increasing hazard,

$$
\frac{\partial \bar{A}}{\partial b}=R^{f} \frac{1}{(1-\Phi(\bar{A}))-\mu \bar{A} d \Phi(\bar{A})}>0 .
$$

To prove Proposition 2 we need to establish the following Lemma first.

Lemma 1 When debt is positive, the multiplier $\mu_{t}$ satisfies the following conditions:

$$
\frac{\partial \mu_{t}}{\partial K_{t}}=\frac{\partial \mu_{t}}{\partial B_{t}}=0
$$


Proof. The envelope conditions for respect to $K_{t}$ and $B_{t}$ imply:

$$
\begin{aligned}
V_{21}\left(K_{t}, B_{t}, S_{t}\right)= & -\frac{\partial \mu_{t}}{\partial K_{t}}\left[R\left(B_{t} / K_{t}\right)+R_{1}\left(B_{t} / K_{t}\right)\left(B_{t} / K_{t}\right)\right] \\
& +\mu_{t}\left[R_{1}\left(B_{t} / K_{t}\right)\left(2 B_{t} / K_{t}^{2}\right)+R_{11}\left(B_{t} / K_{t}\right)\left(B_{t}^{2} / K_{t}^{3}\right)\right] \\
V_{22}\left(K_{t}, B_{t}, S_{t}\right)= & -\frac{\partial \mu_{t}}{\partial B_{t}}\left[R\left(B_{t} / K_{t}\right)+R_{1}\left(B_{t} / K_{t}\right)\left(B_{t} / K_{t}\right)\right] \\
& -\mu_{t}\left[R_{1}\left(B_{t} / K_{t}\right)\left(2 / K_{t}\right)+R_{11}\left(B_{t} / K_{t}\right)\left(B_{t} / K_{t}^{2}\right)\right]
\end{aligned}
$$

Now homogeneity of the value function implies that

$$
\begin{aligned}
0 & =V_{21}\left(K_{t}, B_{t}, S_{t}\right) K_{t}+V_{22}\left(K_{t}, B_{t}, S_{t}\right) B_{t} \\
& =-\left[R\left(B_{t} / K_{t}\right)+R_{1}\left(B_{t} / K_{t}\right)\left(B_{t} / K_{t}\right)\right]\left(\frac{\partial \mu_{t}}{\partial K_{t}} K_{t}+\frac{\partial \mu_{t}}{\partial B_{t}} B_{t}\right)
\end{aligned}
$$

thus confirming that $\mu_{t}$ is indeed homogeneous of degree zero in $K_{t}$ and $B_{t}$.

Now since

$$
\begin{aligned}
V_{21}(K, B, X)= & V_{12}(K, B, X)=\frac{\partial \mu_{t}}{\partial B_{t}}\left[C_{1}\left(K_{t}, K_{t+1}, S_{t}\right)+R_{1}\left(B_{t} / K_{t}\right)\left(B_{t} / K_{t}\right)^{2}\right] \\
& +\mu_{t}\left[R_{1}\left(B_{t} / K_{t}\right)\left(2 B_{t} / K_{t}^{2}\right)+R_{11}\left(B_{t} / K_{t}\right)\left(B_{t}^{2} / K_{t}^{3}\right)\right]
\end{aligned}
$$

equating (A1) and (A2) and simplifying yields

$$
-\frac{\partial \mu_{t}}{\partial K_{t}}\left[R\left(B_{t} / K_{t}\right)+R_{1}\left(B_{t} / K_{t}\right)\left(B_{t} / K_{t}\right)\right]=\frac{\partial \mu_{t}}{\partial B_{t}}\left[C_{1}\left(K_{t}, K_{t+1}, S_{t}\right)+R_{1}\left(B_{t} / K_{t}\right)\left(B_{t} / K_{t}\right)^{2}\right]
$$

Thus,

$$
\frac{\partial \mu_{t}}{\partial K_{t}} R\left(B_{t} / K_{t}\right)+\frac{\partial \mu_{t}}{\partial B_{t}} C_{1}\left(K_{t}, K_{t+1}, S_{t}\right)=\left(\frac{\partial \mu_{t}}{\partial K_{t}} K_{t}+\frac{\partial \mu_{t}}{\partial B_{t}} B_{t}\right) R_{1}\left(B_{t} / K_{t}\right)\left(B_{t} / K_{t}^{2}\right)=0
$$

Therefore, the derivatives of $\mu_{t}$ satisfy the following two conditions

$$
\begin{aligned}
\frac{\partial \mu_{t}}{\partial K_{t}} R\left(B_{t} / K_{t}\right)+\frac{\partial \mu_{t}}{\partial B_{t}} C_{1}\left(K_{t}, K_{t+1}, S_{t}\right) & =0 \\
\left(\frac{\partial \mu_{t}}{\partial K_{t}} K_{t}+\frac{\partial \mu_{t}}{\partial B_{t}} B_{t}\right) & =0
\end{aligned}
$$

But since $B_{t}>0$

$$
R\left(B_{t} / K_{t}\right) B_{t}+C_{1}\left(K_{t}, K_{t+1}, S_{t}\right) K_{t}>0
$$

and we must have that

$$
\frac{\partial \mu_{t}}{\partial K_{t}}=\frac{\partial \mu_{t}}{\partial B_{t}}=0
$$

Proof of Proposition 2. In the case of debt financing only, investment returns can be written as:

$$
R_{t+1}^{I}=\frac{\mu_{t+1}\left[C_{1}\left(K_{t+1}, K_{t+2}, S_{t+1}\right)+R_{1}\left(B_{t+1} / K_{t+1}\right)\left(B_{t+1} / K_{t+1}\right)^{2}\right]}{-\mu_{t} C_{2}\left(K_{t}, K_{t+1}, S_{t}\right)}
$$


Define the function:

$$
G\left(K_{t}, K_{t+1}, S_{t}\right)=\left(\mu_{t}-1\right) B_{t+1}
$$

it follows that

$$
\begin{aligned}
& G_{1}\left(K_{t}, K_{t+1}, S_{t}\right)=-\left(\mu_{t}-1\right)\left[C_{1}\left(K_{t}, K_{t+1}, S_{t}\right)+R_{1}\left(B_{t} / K_{t}\right)\left(B_{t} / K_{t}\right)^{2}\right] \\
& G_{2}\left(K_{t}, K_{t+1}, S_{t}\right)=-\left(\mu_{t}-1\right) C_{2}\left(K_{t}, K_{t+1}, S_{t}\right)
\end{aligned}
$$

Integration of (A6) yields

$$
G\left(K_{t}, K_{t+1}, S_{t}\right)=\int G_{2}\left(K_{t}, K_{t+1}, S_{t}\right) d K_{t+1}=-\left(\mu_{t}-1\right) C\left(K_{t}, K_{t+1}, S_{t}\right)+f_{1}\left(K_{t}, S_{t}\right)
$$

where $f_{1}(\cdot)$ is independent of $K_{t+1}$. Using Lemma 1 we know that the integral of (A5) equals

$G\left(K_{t}, K_{t+1}, S_{t}\right)=-\left(\mu_{t}-1\right) C\left(K_{t}, K_{t+1}, S_{t}\right)-\left(\mu_{t}-1\right) \int R_{1}\left(B_{t} / K_{t}\right)\left(B_{t} / K_{t}\right)^{2} d K_{t}+f_{2}\left(K_{t+1}, S_{t}\right)$

where $f_{2}(\cdot)$ is independent of $K_{t}$. Combining two equations above yields

$$
G\left(K_{t}, K_{t+1}, S_{t}\right)=\left(\mu_{t}-1\right)\left[R\left(B_{t} / K_{t}\right) B_{t}+\bar{D}-C\left(K_{t}, K_{t+1}, S_{t}\right)\right]=\left(\mu_{t}-1\right) B_{t+1}
$$

where the second equality follows from (7) and the fact that $B_{t}>0 \Longrightarrow D_{t}=\bar{D}$. Equation (A3) now implies that:

$$
R_{t+1}^{I}=\frac{C_{1}\left(K_{t+1}, K_{t+2}, S_{t+1}\right)-G_{1}\left(K_{t+1}, K_{t+2}, S_{t+1}\right)}{-C_{2}\left(K_{t}, K_{t+1}, S_{t}\right)+G_{2}\left(K_{t}, K_{t+1}, S_{t}\right)}=\frac{\widetilde{C}_{1}\left(K_{t+1}, K_{t+2}, S_{t+1}\right)}{-\widetilde{C}_{2}\left(K_{t}, K_{t+1}, S_{t}\right)}
$$

To prove Proposition 3 we need to establish the following Lemma first.

Lemma 2 The value of the firm equals the sum of (cum-dividend) equity value and the value of outstanding debt:

$$
q_{t} K_{t}=V\left(K_{t}, B_{t}, S_{t}\right)+\mu_{t} B_{t}\left[R\left(B_{t} / K_{t}\right)+R_{1}\left(B_{t} / K_{t}\right)\left(B_{t} / K_{t}\right)\right]
$$

where $q_{t}=V_{1}\left(K_{t}, B_{t}, S_{t}\right)$ denotes the marginal $q$. Moreover, (A7) implies that marginal $q$ equals Tobin's (average) $q$.

Proof For simplicity consider the case where $\bar{D}=0$. Rewrite the value of the firm as

$$
V\left(K_{t}, B_{t}, S_{t}\right)=\max _{\substack{D_{t}, B_{t+1} \\
K_{t+1}, N_{t}}}\left\{\begin{array}{c}
\left(1-\mu_{t}+\lambda_{t}^{d}\right) D_{t}+\left[\mu_{t}-W\left(N_{t} / K_{t}\right)+\lambda_{t}^{n}\right] N_{t}+\mu_{t}\left[C\left(K_{t}, K_{t+1}, S_{t}\right)\right. \\
\left.+B_{t+1}-R\left(B_{t} / K_{t}\right) B_{t}\right]+\mathrm{E}_{t}\left[M_{t, t+1} V\left(K_{t+1}, B_{t+1}, S_{t+1}\right)\right]
\end{array}\right\}
$$

The complementarity-slackness conditions imply that the first term on the right-hand side is zero and the second equals $W_{1}\left(N_{t} / K_{t}\right)\left(N_{t} / K_{t}\right) N_{t}$.

Next, homogeneity of the value function and the envelope conditions imply that:

$$
\mathrm{E}_{t}\left[M_{t, t+1} V\left(K_{t+1}, B_{t+1}, S_{t+1}\right)\right]=-\mu_{t} C_{2}\left(K_{t}, K_{t+1}, S_{t}\right) K_{t+1}-\mu_{t} B_{t+1}
$$


while homogeneity of $C$ yields

$$
C_{1}\left(K_{t}, K_{t+1}, S_{t}\right) K_{t}=C\left(K_{t}, K_{t+1}, S_{t}\right)-C_{2}\left(K_{t}, K_{t+1}, S_{t}\right) K_{t+1}
$$

Hence the value function collapses to

$$
V\left(K_{t}, B_{t}, S_{t}\right)=W_{1}\left(N_{t} / K_{t}\right)\left(N_{t} / K_{t}\right) N_{t}+\mu_{t}\left[C_{1}\left(K_{t}, K_{t+1}, S_{t}\right) K_{t}-R\left(B_{t} / K_{t}\right) B_{t}\right]
$$

Rearranging, and using the envelope condition, we have:

$$
V\left(K_{t}, B_{t}, S_{t}\right)+\mu_{t}\left[R\left(B_{t} / K_{t}\right) B_{t}+R_{1}\left(B_{t} / K_{t}\right)\left(B_{t} / K_{t}\right) B_{t}\right]=V_{1}\left(K_{t}, B_{t}, S_{t}\right) K_{t}
$$

Proof of Proposition 3. By definition stock returns are given by

$$
R_{t+1}^{S}=\frac{V^{e}\left(K_{t+1}, B_{t+1}, S_{t+1}\right)+\left[D_{t+1}-W\left(N_{t+1} / K_{t+1}, S_{t+1}\right) N_{t+1}\right]}{V^{e}\left(K_{t}, B_{t}, S_{t}\right)},
$$

where

$$
V^{e}\left(K_{t}, B_{t}, S_{t}\right) \equiv V\left(K_{t}, B_{t}, S_{t}\right)-\left[D_{t}-W\left(N_{t} / K_{t}, S_{t}\right) N_{t}\right]
$$

is the (current period) value of the firm to shareholders after new issues take place and dividends are paid.

Again consider the simple case where $\bar{D}=0$. Starting from the definition of investment returns (19), we have

$$
\begin{aligned}
R^{I} & =\frac{V_{1}\left(K_{t+1}, B_{t+1}, S_{t+1}\right)}{-\mu_{t} C_{2}\left(K_{t}, K_{t+1}, S_{t}\right)}=\frac{V_{1}\left(K_{t+1}, B_{t+1}, S_{t+1}\right)}{\mu_{t}\left[C_{1}\left(K_{t}, K_{t+1}, S_{t}\right) K_{t}-C\left(K_{t}, K_{t+1}, S_{t}\right)\right]} \\
& =\frac{V\left(K_{t+1}, B_{t+1}, S_{t+1}\right)+\mu_{t+1} B_{t+1}\left[R\left(B_{t+1} / K_{t+1}\right)+R_{1}\left(B_{t+1} / K_{t+1}\right)\left(B_{t+1} / K_{t+1}\right)\right]}{V\left(K_{t}, B_{t}, S_{t}\right)-\mu_{t} D_{t}+\mu_{t} B_{t+1}+N_{t}\left[\mu_{t}-W_{1}\left(N_{t} / K_{t}\right)\left(N_{t} / K_{t}\right)\right]}
\end{aligned}
$$

where the second equality follows from homogeneity of $C(\cdot)$, and the third from the envelope condition and Lemma 2. Next, observe that the complementarity slackness conditions imply:

$$
\begin{aligned}
D_{t}\left(1-\mu_{t}\right) & =0 \\
N_{t}\left[\mu_{t}-W_{1}\left(N_{t} / K_{t}\right)\left(N_{t} / K_{t}\right)\right] & =W\left(N_{t} / K_{t}\right) N_{t}
\end{aligned}
$$

Thus

$$
R_{t+1}^{I}=\frac{V\left(K_{t+1}, B_{t+1}, S_{t+1}\right)+\mu_{t+1} B_{t+1}\left[R\left(B_{t+1} / K_{t+1}\right)+R_{1}\left(B_{t+1} / K_{t+1}\right)\left(B_{t+1} / K_{t+1}\right)\right]}{V\left(K_{t}, B_{t}, S_{t}\right)-D_{t}+\mu_{t} B_{t+1}+W\left(N_{t} / K_{t}\right) N_{t}}
$$

Using the definitions of $R_{t+1}^{S}, R_{t+1}^{B}$ it follows that:

$$
R_{t+1}^{I}=\left(1-\omega_{t}\right) R_{t+1}^{S}+\omega_{t} R_{t+1}^{B}
$$


where the leverage ratio, $\omega_{t}$, equals

$$
\omega_{t}=\frac{\mu_{t} B_{t+1}}{V^{e}\left(K_{t}, B_{t}, S_{t}\right)+\mu_{t} B_{t+1}} .
$$

With this result established, it follows immediately that

$$
1=\mathrm{E}_{t}\left[M_{t, t+1} R_{t+1}^{S}\left(1-\omega_{t}\right)\right]+\mathrm{E}_{t}\left[M_{t, t+1} R_{t+1}^{B} \omega_{t}\right]=\left(1-\omega_{t}\right) \mathrm{E}_{t}\left[M_{t, t+1} R_{t+1}^{S}\right]+\omega_{t}
$$

or, simply

$$
\mathrm{E}_{t}\left[M_{t, t+1} R_{t+1}^{S}\right]=1
$$

\section{B Data Construction}

Macroeconomic data comes from NIPA, published by the BEA, and the Flow of Funds Accounts, available from the Federal Reserve System. These data are cross-referenced and mutually consistent, so they form, for practical purposes, a unique source of information. Most of our experiments use data for the Nonfinancial Corporate Sector. Specifically Table F102 is used to construct measures of profits before (item FA106060005) and after tax accruals (item FA106231005). To these measures we add both consumption capital (item FA106300015) and inventory valuation (item FA106020601) adjustments to obtain a better indicator of actual cash flows. Investment spending is gross investment (item 105090005). The capital stock comes from Table B102 (Item FL102010005). Since stock valuations include cash flows from operations abroad, we also include in our measures of profits the value of foreign earnings abroad (item FA266006003) and that of net foreign holdings to the capital stock (items FL103092005 minus FL103192005, from Table L230) and investment (the change in net holdings). Financial liabilities come also from Table B102. They are constructed by subtracting financial assets, including trade receivables, (Item FL104090005) from liabilities in credit market instruments (Item FL104104005) plus trade payables (Item FL103170005). Interest payments come from NIPA Table 1.16, line 35. All these are available at quarterly frequency and require no further adjustments. Series for the aggregate economy come from NIPA.

Financial data come from CRSP and Ibbotson. We use the ten size portfolios of NYSE stocks (CRSP series DECRET1 to DECRET10). Corporate bond data comes from Ibbotson's index of Long Term Corporate Bonds. The default premium is defined as the difference between the yields on AAA and Baa corporate bonds, from CRSP. Term premium, defined as the yield on 10 year notes minus that on three-month Treasury bills, and the dividend-price ratio of the equally weighted NYSE portfolio (constructed from CRSP EWRETD and EWRETX). ${ }^{36}$

\footnotetext{
${ }^{36}$ Dividend-price ratios are also normalized so that scaled and non-scaled returns are comparable.
} 